\title{
Association between meteorological factors and reported cases of hand, foot, and mouth disease from 2000 to 2015 in Japan
}

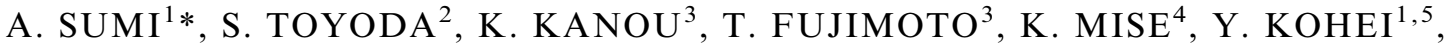 \\ A. KOYAMA $^{6}$ AND N. KOBAYASHI ${ }^{1}$ \\ ${ }^{1}$ Department of Hygiene, Sapporo Medical University School of Medicine, Hokkaido, Japan \\ ${ }^{2}$ Department of Information Engineering, College of Industrial Technology, Hyogo, Japan \\ ${ }^{3}$ Infectious Disease Surveillance Center, National Institute of Infectious Diseases, Tokyo, Japan \\ ${ }^{4}$ Admission Center, Sapporo Medical University, Hokkaido, Japan \\ ${ }^{5}$ Department of Nursing, Faculty of Human Science, Hokkaido Bunkyo University, Hokkaido, Japan \\ ${ }^{6}$ Yurakucho Sakura Clinic, Tokyo, Japan
}

Received 13 March 2017; Final revision 2 July 2017; Accepted 19 July 2017;

first published online 22 August 2017

\section{SUMMARY}

The purpose of this study was to clarify the association between hand, foot, and mouth disease (HFMD) epidemics and meteorological conditions. We used HFMD surveillance data of all 47 prefectures in Japan from January 2000 to December 2015. Spectral analysis was performed using the maximum entropy method (MEM) for temperature-, relative humidity-, and total rainfall-dependent incidence data. Using MEM-estimated periods, long-term oscillatory trends were calculated using the least squares fitting (LSF) method. The temperature and relative humidity thresholds of HFMD data were estimated from the LSF curves. The average temperature data indicated a lower threshold at $12{ }^{\circ} \mathrm{C}$ and a higher threshold at $30^{\circ} \mathrm{C}$ for risk of HFMD infection. Maximum and minimum temperature data indicated a lower threshold at $6{ }^{\circ} \mathrm{C}$ and a higher threshold at $35^{\circ} \mathrm{C}$, suggesting a need for HFMD control measures at temperatures between 6 and $35^{\circ} \mathrm{C}$. Based on our findings, we recommend the use of maximum and minimum temperatures rather than the average temperature, to estimate the temperature threshold of HFMD infections. The results obtained might aid in the prediction of epidemics and preparation for the effect of climatic changes on HFMD epidemiology.

Key words: Hand, foot, and mouth disease, relative humidity, spectral analysis, surveillance, temperature.

\section{INTRODUCTION}

Meteorological factors have been recognized as risk factors associated with hand, foot, and mouth disease (HFMD) epidemics [1-3]. We previously demonstrated that in Wuhan, China, HFMD cases are

\footnotetext{
* Author for correspondence: A. Sumi, Department of Hygiene, Sapporo Medical University School of Medicine, S-1, W-17, Chuo-ku, Sapporo 060-8556, Japan.

(Email: sumi@sapmed.ac.jp)
}

frequently reported with temperatures of $10-25^{\circ} \mathrm{C}$ and reports decrease at temperatures below $10{ }^{\circ} \mathrm{C}$ or above $25^{\circ} \mathrm{C}$ [4]. This inverse $V$-shaped relationship between the reported number of HFMD cases and temperature has also been observed during HFMD epidemics in Taiwan and mainland China [5, 6]. Our previous results suggest that bimodal seasonal peaks in HFMD epidemics are attributable to enterovirus A71 (EV-A71) epidemics. Current hypotheses explaining the seasonal pattern of EV-A71 infection include 
host immune competence fluctuations mediated by seasonal factors, such as melatonin or vitamin D levels [7] as well as seasonal behavioural factors unrelated to weather, such as school attendance and indoor crowding [8]. However, human behavioural factors alone do not appear to account for the seasonal pattern observed in certain cases of EV-A71 infection, including those that occur among school-aged children or in association with household crowding [9].

It has been reported that viruses are devoid of thermostatic mechanisms and that their reproduction and survival rates are strongly affected by fluctuations in temperature, as are those of parasites and bacteria $[10,11]$. Thus, investigation of the effect of meteorological factors on the epidemiology of infectious diseases, including HFMD, is necessary for practitioners and public health policy makers to control disease and for planning public health media events to promote preventive activities. Based on our previous study in Wuhan, China [4], controlling the spread of viral infections at temperatures ranging from 10 to $25^{\circ} \mathrm{C}$ should be considered, to help prevent HFMD infections. In Japan, no concrete temperature range has been associated with HFMD epidemics. Many people believe that HFMD is an infection that occurs in the summer season, but the timing of such infections is too ambiguous to prevent and predict HFMD incidence. Further investigation is required to clarify the association between HFMD and meteorological conditions in Japan.

The purpose of this study was to further clarify the association between HFMD epidemics and meteorological conditions. For this, we used HFMD surveillance data of all 47 prefectures in Japan, collected by Japan's National Epidemiological Surveillance of Infectious Diseases (NESID) [12]. Japan extends from latitude $45^{\circ} \mathrm{N}$ to $20^{\circ} \mathrm{N}$; therefore, meteorological conditions vary widely. We considered that a subset of the HFMD surveillance data might be useful to clarify the association between HFMD epidemics and meteorological conditions.

Our study used HFMD surveillance data and meteorological data of all prefectures in Japan, based on a study conducted in Japan's southern prefectures reporting that ambient temperature and relative humidity were associated with increased occurrence of HFMD [13]. To precisely estimate the relationship between HFMD data throughout Japan and meteorological data, we proposed a method with a clear criterion of adequate estimation. The analyses included spectral analysis using the maximum entropy method (MEM) and least squares method (LSM) [14, 15].
The obtained results might assist in the prediction of epidemics and preparation for the effects of climatic changes on infectious disease epidemiology.

\section{DATA \\ HFMD data}

The time series data analysed in this study represent the weekly reported HFMD incidence data for all 47 prefectures of Japan. These data were obtained from the Infectious Diseases Weekly Report Japan [16]. The incidence data for each prefecture indicates the number of HFMD cases reported weekly per paediatric sentinel clinic in the prefecture. There are approximately 3000 paediatric sentinel clinics nationwide. The number of sentinel clinics (3000) has been set to a standard error rate of annual number of HFMD patients in all of Japan of $<5 \%$ [17]. Sentinel HFMD cases were defined by clinical presentation, that is, papular or vesicular rash on the hands, feet, mouth, or buttocks, with or without fever [16]. The data for each prefecture were gathered over 835 weeks $(835$ data points) from January 2000 to December 2015. Portions of the 2011 data for Miyagi Prefecture (week 10) and Fukushima Prefecture (weeks 10, 11, 13, and 14) were unavailable because of the Great East Japan Earthquake. These missing data were replaced with the mean values, which were calculated using the data immediately before and after the missing observations. The 47 prefectures of Japan are shown in Figure 1.

\section{Meteorological data}

The Automated Meteorological Data Acquisition System (AMeDAS) developed by the Japan Meteorological Agency (JMA) is a high-resolution surface observation network. The AMeDAS comprises 1300 stations throughout Japan, of which 840 stations cover temperature, relative humidity, precipitation, and so on; the average distance between stations is $21 \mathrm{~km}$ [18]. In the present study, we used daily data collected at the AMeDAS stations in the 47 prefectural capitals. These data were obtained from the JMA website [19] and included average temperature, maximum temperature, minimum temperature, relative humidity, and precipitation. Daily data were obtained for a total of 5845 days from 2000 to 2015 (5845 data points).

Descriptive statistics for the weekly meteorological data are shown in Table 1. Notably, the mean values 


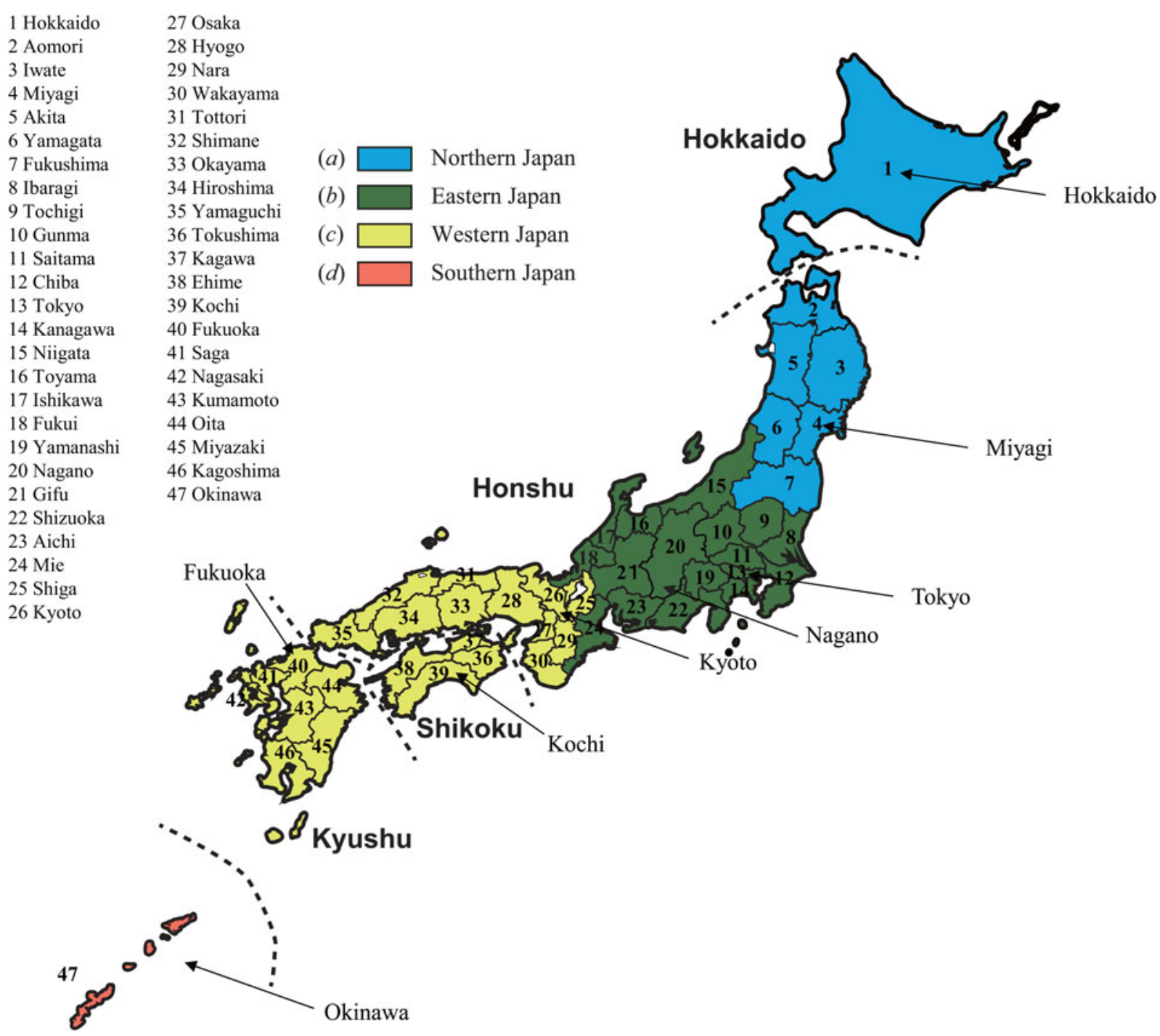

Fig. 1. Distribution of the 47 prefectures of Japan. Dashed lines indicate boundaries of the four main islands constituting Japan: Hokkaido, Hoshu, Shikoku, and Kyushu. The eight prefectures are used as representative sites: (a) Hokkaido and Miyagi Prefectures in northern Japan (blue); (b) Tokyo and Nagano in eastern Japan (green); (c) Kyoto, Kochi, and Fukuoka in western Japan (yellow); and (d) Okinawa in southern Japan (orange).

of average temperature rise with lower latitudes: $9 \cdot 3{ }^{\circ} \mathrm{C}$ in Hokkaido (latitude $43^{\circ} \mathrm{N}$ ), $12.8^{\circ} \mathrm{C}$ in Miyagi $\left(38^{\circ} \mathrm{N}\right), 16 \cdot 7^{\circ} \mathrm{C}$ in Tokyo $\left(35^{\circ} \mathrm{N}\right), 12 \cdot 3^{\circ} \mathrm{C}$ in Nagano $\left(36^{\circ} \mathrm{N}\right), 16 \cdot 2{ }^{\circ} \mathrm{C}$ in Kyoto $\left(35^{\circ} \mathrm{N}\right), 17 \cdot 4^{\circ} \mathrm{C}$ in Kochi $\left(33^{\circ} \mathrm{N}\right), 17 \cdot 4^{\circ} \mathrm{C}$ in Fukuoka $\left(33^{\circ} \mathrm{N}\right)$, and $23 \cdot 3{ }^{\circ} \mathrm{C}$ in Okinawa $\left(26^{\circ} \mathrm{N}\right)$.

\section{METHODS}

\section{Selection method of eight prefectures as representative sites}

Based on geographical division by the JMA [19], we selected eight from among the 47 prefectures in Japan as representative sites. For providing weather information, the JMA divides the entire country into the following four areas: northern, eastern, western, and southern Japan. In this study, we selected one, two, or three prefectures from each area as illustrative examples (Fig. 1), as follows: (a) Hokkaido and Miyagi from northern Japan; (b) Tokyo and Nagano from eastern Japan; (c) Kyoto, Kochi, and Fukuoka from western Japan; and (d) Okinawa from southern Japan; this gave a total of eight prefectures. Among them, Hokkaido has a subpolar climate and Okinawa has a subtropical climate. The other six prefectures (Miyagi, Tokyo, Nagano Kyoto, Kochi, and Fukuoka) have a temperate climate [20]. 
Table 1. Summary statistics for weekly meteorological conditions of eight prefectures in Japan used as representative site

\begin{tabular}{|c|c|c|c|c|c|}
\hline Prefectures & Latitude & Longitude & Variable & Mean & S.D. \\
\hline \multirow[t]{5}{*}{ Hokkaido } & $43^{\circ} \mathrm{N}$ & $141^{\circ} \mathrm{E}$ & $T\{\mathrm{~A}\}\left({ }^{\circ} \mathrm{C}\right)$ & $9 \cdot 3$ & $9 \cdot 4$ \\
\hline & & & $T\{\mathrm{M}\}\left({ }^{\circ} \mathrm{C}\right)$ & $13 \cdot 2$ & $10 \cdot 0$ \\
\hline & & & $T\{\mathrm{~m}\}\left({ }^{\circ} \mathrm{C}\right)$ & $5 \cdot 7$ & $9 \cdot 3$ \\
\hline & & & RH (\%) & $68 \cdot 5$ & $6 \cdot 8$ \\
\hline & & & $\mathrm{RF}(\mathrm{mm})$ & $22 \cdot 5$ & $22 \cdot 3$ \\
\hline \multirow[t]{5}{*}{ Miyagi } & $38^{\circ} \mathrm{N}$ & $140^{\circ} \mathrm{E}$ & $T\{\mathrm{~A}\}\left({ }^{\circ} \mathrm{C}\right)$ & $12 \cdot 8$ & $8 \cdot 2$ \\
\hline & & & $T\{\mathrm{M}\}\left({ }^{\circ} \mathrm{C}\right)$ & $16 \cdot 9$ & $8 \cdot 2$ \\
\hline & & & $T\{\mathrm{~m}\}\left({ }^{\circ} \mathrm{C}\right)$ & $9 \cdot 3$ & $8 \cdot 4$ \\
\hline & & & RH (\%) & $71 \cdot 0$ & $9 \cdot 3$ \\
\hline & & & $\mathrm{RF}(\mathrm{mm})$ & $24 \cdot 5$ & $35 \cdot 1$ \\
\hline \multirow[t]{5}{*}{ Tokyo } & $35^{\circ} \mathrm{N}$ & $139^{\circ} \mathrm{E}$ & $T\{\mathrm{~A}\}\left({ }^{\circ} \mathrm{C}\right)$ & $16 \cdot 7$ & $7 \cdot 7$ \\
\hline & & & $T\{\mathrm{M}\}\left({ }^{\circ} \mathrm{C}\right)$ & $20 \cdot 5$ & $7 \cdot 7$ \\
\hline & & & $T\{\mathrm{~m}\}\left({ }^{\circ} \mathrm{C}\right)$ & $13 \cdot 3$ & $8 \cdot 0$ \\
\hline & & & RH (\%) & $60 \cdot 3$ & $11 \cdot 6$ \\
\hline & & & $\mathrm{RF}(\mathrm{mm})$ & $31 \cdot 3$ & $42 \cdot 4$ \\
\hline \multirow[t]{5}{*}{ Nagano } & $36^{\circ} \mathrm{N}$ & $138^{\circ} \mathrm{E}$ & $T\{\mathrm{~A}\}\left({ }^{\circ} \mathrm{C}\right)$ & $12 \cdot 3$ & $9 \cdot 3$ \\
\hline & & & $T\{\mathrm{M}\}\left({ }^{\circ} \mathrm{C}\right)$ & $17 \cdot 8$ & $9 \cdot 8$ \\
\hline & & & $T\{\mathrm{~m}\}\left({ }^{\circ} \mathrm{C}\right)$ & $7 \cdot 9$ & $9 \cdot 3$ \\
\hline & & & RH (\%) & $71 \cdot 4$ & $7 \cdot 4$ \\
\hline & & & $\mathrm{RF}(\mathrm{mm})$ & $18 \cdot 7$ & $21 \cdot 8$ \\
\hline \multirow[t]{5}{*}{ Kyoto } & $35^{\circ} \mathrm{N}$ & $135^{\circ} \mathrm{E}$ & $T\{\mathrm{~A}\}\left({ }^{\circ} \mathrm{C}\right)$ & $16 \cdot 2$ & $8 \cdot 6$ \\
\hline & & & $T\{\mathrm{M}\}\left({ }^{\circ} \mathrm{C}\right)$ & $21 \cdot 2$ & $8 \cdot 8$ \\
\hline & & & $T\{\mathrm{~m}\}\left({ }^{\circ} \mathrm{C}\right)$ & $12 \cdot 1$ & $8 \cdot 5$ \\
\hline & & & RH (\%) & $64 \cdot 3$ & $6 \cdot 2$ \\
\hline & & & $\mathrm{RF}(\mathrm{mm})$ & 28.6 & $35 \cdot 0$ \\
\hline \multirow[t]{5}{*}{ Kochi } & $33^{\circ} \mathrm{N}$ & $133^{\circ} \mathrm{E}$ & $T\{\mathrm{~A}\}\left({ }^{\circ} \mathrm{C}\right)$ & $17 \cdot 4$ & $7 \cdot 6$ \\
\hline & & & $T\{\mathrm{M}\}\left({ }^{\circ} \mathrm{C}\right)$ & $22 \cdot 2$ & $7 \cdot 1$ \\
\hline & & & $T\{\mathrm{~m}\}\left({ }^{\circ} \mathrm{C}\right)$ & $13 \cdot 2$ & $8 \cdot 2$ \\
\hline & & & RH (\%) & $68 \cdot 7$ & $8 \cdot 9$ \\
\hline & & & $\mathrm{RF}(\mathrm{mm})$ & $50 \cdot 4$ & $42 \cdot 2$ \\
\hline \multirow[t]{5}{*}{ Fukuoka } & $33^{\circ} \mathrm{N}$ & $130^{\circ} \mathrm{E}$ & $T\{\mathrm{~A}\}\left({ }^{\circ} \mathrm{C}\right)$ & $17 \cdot 4$ & $7 \cdot 7$ \\
\hline & & & $T\{\mathrm{M}\}\left({ }^{\circ} \mathrm{C}\right)$ & $21 \cdot 3$ & $7 \cdot 9$ \\
\hline & & & $T\{\mathrm{~m}\}\left({ }^{\circ} \mathrm{C}\right)$ & $14 \cdot 0$ & $7 \cdot 8$ \\
\hline & & & RH (\%) & $66 \cdot 1$ & $7 \cdot 9$ \\
\hline & & & $\mathrm{RF}(\mathrm{mm})$ & $31 \cdot 7$ & $45 \cdot 4$ \\
\hline \multirow[t]{5}{*}{ Okinawa } & $26^{\circ} \mathrm{N}$ & $127^{\circ} \mathrm{E}$ & $T\{\mathrm{~A}\}\left({ }^{\circ} \mathrm{C}\right)$ & $23 \cdot 3$ & $4 \cdot 5$ \\
\hline & & & $T\{\mathrm{M}\}\left({ }^{\circ} \mathrm{C}\right)$ & $26 \cdot 0$ & $4 \cdot 6$ \\
\hline & & & $T\{\mathrm{~m}\}\left({ }^{\circ} \mathrm{C}\right)$ & $21 \cdot 1$ & $4 \cdot 7$ \\
\hline & & & RH (\%) & $72 \cdot 4$ & $7 \cdot 9$ \\
\hline & & & $\mathrm{RF}(\mathrm{mm})$ & $41 \cdot 7$ & $64 \cdot 5$ \\
\hline
\end{tabular}

Figure 1 shows the results for eight of the representative sites. In Table 1, the eight prefectures are arranged from northern to southern Japan by latitude and longitude.

\section{Data analysis}

Setting up the time series data for analysis

The sampling interval differed for the HFMD data (weekly) and meteorological data (daily). To analyse these two datasets together, it was necessary to choose equal sampling intervals. Therefore, we calculated weekly data for the meteorological variables (835 data points) from the original daily data (5845), to conform to the weekly HFMD data. All meteorological parameters studied and values used for testing the associations are summarized as supplementary information (see online Supplementary Table S1). For example, the weekly average maximum temperature was calculated by averaging the daily maximum temperature for 1 week. The weekly meteorological variables are as follows: $T\{\mathrm{~A}\}$, average temperature $\left({ }^{\circ} \mathrm{C}\right) ; T\{\mathrm{M}\}$, maximum temperature $\left({ }^{\circ} \mathrm{C}\right) ; T\{\mathrm{~m}\}$, minimum temperature $\left({ }^{\circ} \mathrm{C}\right) ; \mathrm{RH}$, relative humidity $(\%)$; $\mathrm{RF}$, total rainfall (mm).

To explain the present method, we used weekly HFMD data of Fukuoka Prefecture (Fig. 2a), which is located in western Japan (Fig. 1).

\section{Correlation between HFMD data and meteorological data}

The average occurrence of HFMD in the different domains of average temperature ( $T\{\mathrm{~A}\}), T$ to $T+$ $\Delta T$, was calculated using the following formula [21]:

$N_{T\{\mathrm{~A}\}}=\frac{\sum_{i}^{n} C_{i} f\left(t_{i}\right)}{\sum_{i}^{n} f\left(t_{i}\right)}$,

where $i$ is the sequence from 0 to $n(=834$, corresponding to the data point [835] minus one), $t_{i}$ is $T\{\mathrm{~A}\}$ for the $i$ th week period, $C_{i}$ is the total number of disease cases per sentinel clinic in the $i$ th week, and $f\left(t_{i}\right)$ is a function with the following values:

$f\left(t_{i}\right)\left\{\begin{array}{l}=1, \text { when } T \leq t_{i}<T+\Delta T \\ =0, \text { otherwise }\end{array}\right.$

The numerator on the right side of equation (1) represents the sum of all $C_{i}$ comprising the 1-week average temperature $\left(t_{i}\right)$ within the temperature domain of $T$ to $T+\Delta T$ during the data period. The denominator is the total number of occasions in which $T<t_{i}<T+\Delta T$ is satisfied during the same data period.

Similarly, average occurrences of HFMD infections in the different variable domains for maximum temperature $\left(N_{T\{\mathrm{M}\}}\right)$, minimum temperature $\left(N_{T\{\mathrm{~m}\}}\right)$, $\mathrm{RH}\left(N_{\mathrm{RH}}\right)$, and $\mathrm{RF}\left(N_{\mathrm{RF}}\right)$ were determined. The variables $t_{i}, T$, and $\Delta T$ for $T\{\mathrm{~A}\}$ in equations (1) and (2) were replaced with $t \mathrm{M}_{i}, T \mathrm{M}$, and $\Delta T \mathrm{M}$, respectively, for $T\{\mathrm{M}\}$; with $t \mathrm{~m}_{i}, T \mathrm{~m}$, and $\Delta T \mathrm{~m}$, respectively, for $T\{\mathrm{~m}\}$; with $h_{i}, H$, and $\Delta H$, respectively, for $\mathrm{RH}$; and 
A. Sumi and others

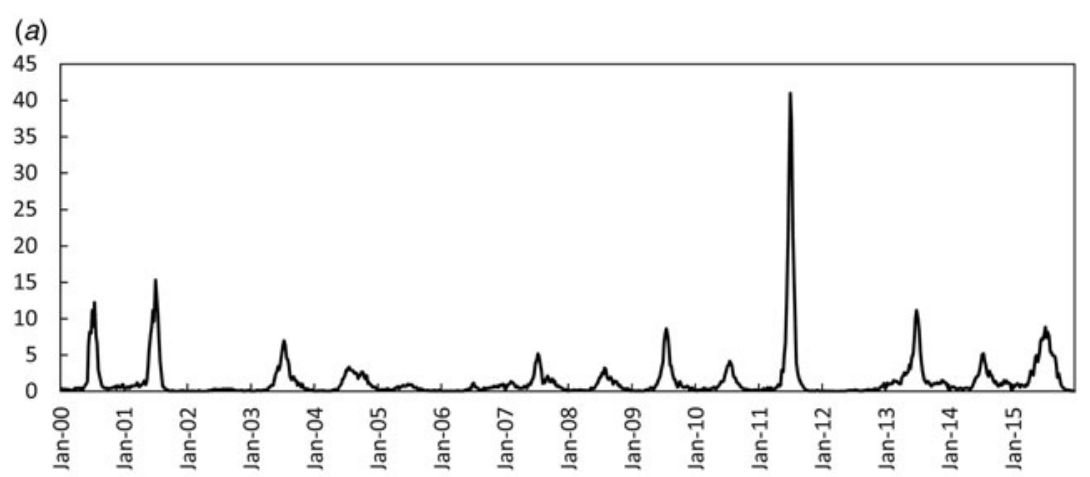

(b)

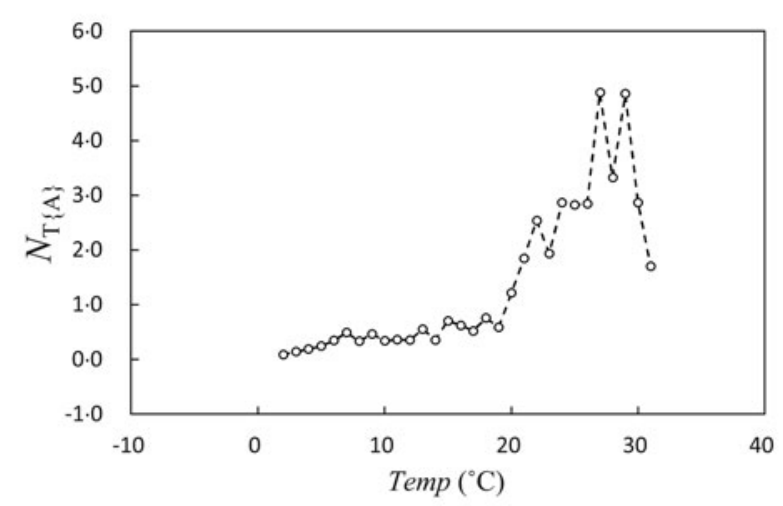

(c)

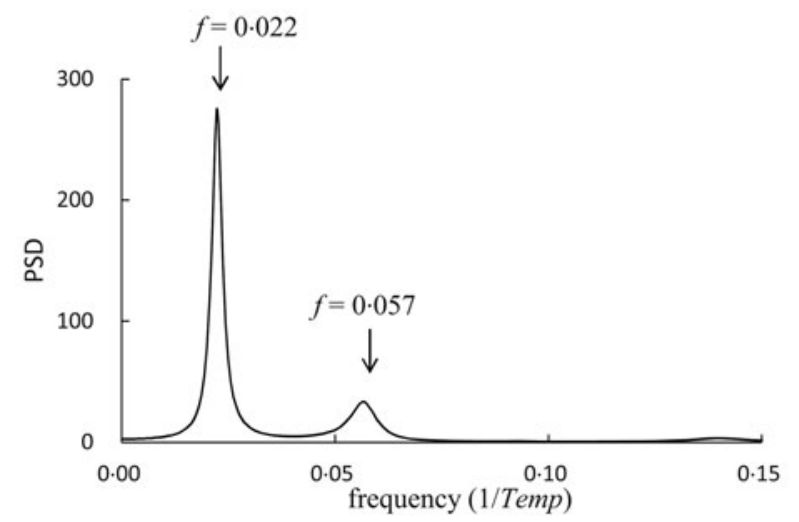

(d)

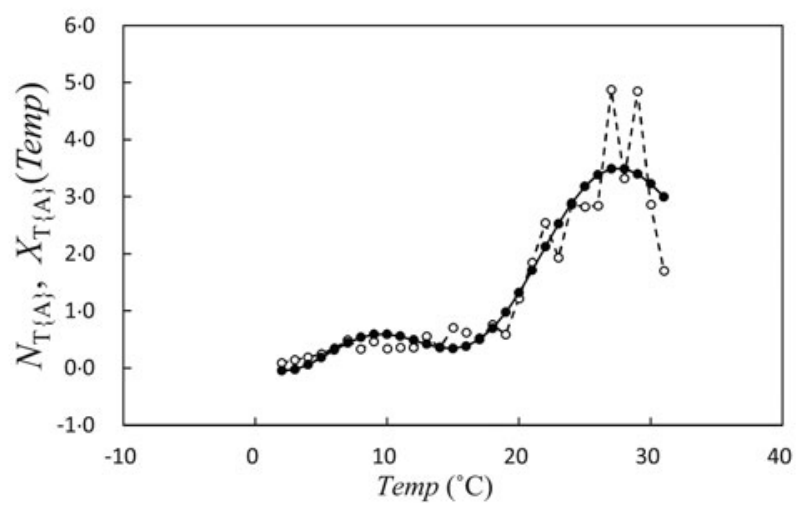

Fig. 2. Procedures of the present analysis method, where incidence data of Fukuoka Prefecture are used an example. (a) Weekly incidence of HFMD per sentinel clinic from 2000 to 2015. (b) Average occurrence of HFMD infections against average temperature (T\{A\}), $N_{T\{\mathrm{~A}\}}$ in equation (1). (c) Power spectral densities of $N_{T\{\mathrm{~A}\}}$. (d) Comparison of the least squares fitting curve $X_{T\{\mathrm{~A}\}}(\mathrm{Temp})$ in equation (4) (solid line) with the original data $N_{T\{\mathrm{~A}\}}$ in equation (1) (dashed line). 
with $r_{i}, R$, and $\Delta R$, respectively, for RF. Values for $\Delta T, \Delta T \mathrm{M}, \Delta T \mathrm{~m}, \Delta H$, and $\Delta R$ were determined using semi-empirical procedures, as previously described [4]; these were $1,1,1{ }^{\circ} \mathrm{C}, 5 \%$, and $30 \mathrm{~mm}$, respectively. As a result, we obtained temperature-dependent incidence data $\left(N_{T\{\mathrm{~A}\}}, N_{T\{\mathrm{M}\}}\right.$, and $\left.N_{T\{\mathrm{~m}\}}\right)$, RH-dependent incidence data $\left(N_{\mathrm{RH}}\right)$, and RF-dependent incidence data $\left(N_{\mathrm{RF}}\right)$.

In Figure $2 b$, we show the temperature-dependent incidence data, that is, the value of $N_{T\{\mathrm{~A}\}}$ against Temp [temperature $\left({ }^{\circ} \mathrm{C}\right)$ ] for Fukuoka Prefecture.

\section{Spectral analysis and LSM}

(i) Theoretical background. We assumed that temperature-dependent incidence data, $N_{T\{\mathrm{~A}\}}$ against Temp (Fig. 2b), was composed of systematic and fluctuating parts [22]:

$N_{T\{\mathrm{~A}\}}=$ systematic part + fluctuating part

The systematic part in equation (3) is regarded as the underlying variation in the original data; the fluctuating part, including undeterministic components such as noise, was obtained as the residual data when the underlying part was subtracted from the original data. Estimation of the underlying variation is a key point.

The underlying variation in the original data $N_{T\{\mathrm{~A}\}}$ against Temp (Fig. 2b) is assumed to be described by the function $X_{T\{\mathrm{~A}\}}(\mathrm{Temp})$, as follows:

$$
\begin{aligned}
X_{T\{\mathrm{~A}\}}(\text { Temp })= & A_{0} \\
& +\sum_{i=1}^{N} A_{i} \cos \left\{2 \pi f_{i}\left(\text { Temp }+\theta_{i}\right)\right\},
\end{aligned}
$$

which is calculated using the LSM for $N_{T\{\mathrm{~A}\}}$ with unknown parameters $f_{i}, A_{0}$, and $A_{i}(i=1,2,3, \ldots, N)$, where $f_{i}\left(=1 / T_{i} ; T_{i}\right.$ is the period) is the frequency of the $i$ th component, $A_{0}$ is a constant that indicates the average value of $N_{T\{\mathrm{~A}\}}, A_{i}$ and $\theta_{i}$ are the amplitude and phase of the $i$ th component, respectively, and $N$ is the total number of components. The values of $N$ were determined using a semi-empirical procedure, as previously described [4]. In the same manner, the formulations of the least squares fitting (LSF) curve to $N_{\mathrm{RH}}$ and $N_{\mathrm{RF}}$ are described by the function $h[\mathrm{RH}(\%)]$ and by the function $r$ [RF (mm)], respectively, as follows:

$$
\begin{aligned}
& X_{\mathrm{RH}}(h)=A_{0}+\sum_{i=1}^{N} A_{i} \cos \left\{2 \pi f_{i}\left(h+\theta_{i}\right)\right\}, \\
& X_{\mathrm{RF}}(r)=A_{0}+\sum_{i=1}^{N} A_{i} \cos \left\{2 \pi f_{i}\left(r+\theta_{i}\right)\right\} .
\end{aligned}
$$

The LSM using equations (4)-(6) must be nonlinear. Linearization of this non-linearity is required to obtain unique optimum values of these parameters. In the present study, linearization of equations (4)-(6) is achieved using the MEM-estimated frequency $f_{i}$.

(ii) Determination of $f_{i}$ (spectral analysis). To estimate $f_{i}$ in equation (4), spectral analysis based on MEM was conducted for $N_{T\{\mathrm{~A}\}}$ against Temp (Fig. 2b). Spectral analysis has been applied to spatial series data $[23,24]$ and time series data [25, 26]. MEM spectral analysis has a high degree of resolution and is useful for clarifying periodicities within short data series, such as the data examined in this study $[25,26]$. Formulation of the MEM power spectral density (PSD) is described in the Appendix.

The value of $f_{i}$ in equation (4) is determined by the position of the spectral peak in the PSD, shown in Figure $2 c$. In the figure, prominent spectral lines were observed at $f=0.022$ and $f=0.057$, which corresponded to $45 \cdot 5$ and $17 \cdot 5$ temperature periodic modes, respectively, owing to a large difference between the beginning and end parts of the data and asymmetrical pattern of the data $N_{T\{\text { A }\}}$ against Temp (Fig. 2b).

(iii) Determination of $A_{0}, A_{i}$ and $\theta_{i}$, and $N$ (least squares analysis). Using two frequency modes $(N=2), f=0.022$ and $f=0.057$ observed in Figure $2 c$ with $X_{T\{\mathrm{~A}\}}$ (Temp) in equation (4), the optimum values for parameters $A_{0}, A_{i}$, and $\theta_{i}(i=1,2)$ in equation (4) are determined exactly from the optimum LSF curve calculation. In Figure $2 d$, the LSF curve $X_{T\{\mathrm{~A}\}}(\mathrm{Temp})$ thus calculated is shown with the original data $N_{T\{\mathrm{~A}\}}$.

The reproducibility level of $N_{T\{\mathrm{~A}\}}, N_{T\{\mathrm{M}\}}$, and $N_{T\{\mathrm{~m}\}}$ by equation (4), $N_{\mathrm{RH}}$ by equation (5), and $N_{\mathrm{RF}}$ by equation (6) were evaluated by Pearson's correlation $(\rho)$ using IBM SPSS Statistics for Windows, Version 22.0 (IBM Corp., Armonk, New York, USA). A two-tailed analysis was used for all statistical tests and a $P$ value of $\leqslant 0 \cdot 05$ was considered statistically significant.

\section{RESULTS}

\section{Case description}

From January 2000 to December 2015, a total 2521 199 cases of HFMD were reported in Japan. Children under 5 years of age accounted for over $80 \cdot 4 \%$ of the reported cases from 2000 to 2014 [16].

\section{Temporal variations in HFMD data}

The eight weekly incidence datasets gathered from January 2000 to December 2015 are shown in 
Figure 3. All weekly incidence data showed an annual cycle. For Okinawa (Fig. 3 h), bimodal cycles of epidemics were clearly observed in 2002 and 2011.

\section{Correlations between HFMD cases and $T\{A\}, T\{M\}$, and $T\{\mathbf{m}\}$}

Using HFMD data (Fig. 3) and data for $T\{\mathrm{~A}\}, T\{\mathrm{M}\}$, and $T\{\mathrm{~m}\}$, we obtained $N_{T\{\mathrm{~A}\}}, N_{T\{\mathrm{M}\}}$, and $N_{T\{\mathrm{~m}\}}$ [equation (1)], respectively. The results of $N_{T\{\mathrm{~A}\}}$ are shown in Figure 4, and those of $N_{T\{\mathrm{M}\}}$ and $N_{T\{\mathrm{~m}\}}$ are listed in the Supplementary Material (see online Supplementary Figs S1 and S2, respectively).

We conducted MEM spectral analyses for $N_{T\{\mathrm{~A}\}}$ for the eight prefectures; MEM-PSDs are shown in Figure 5. In each PSD, two prominent spectral lines were observed. By using the two periodic modes for each prefecture observed in Figure 5, the optimum LSF curve, $X_{T\{\mathrm{~A}\}}(\mathrm{Temp})$ [equation (3)], to $N_{T\{\mathrm{~A}\}}$ data (Fig. 4) was calculated; the $X_{T\{\mathrm{~A}\}}$ (Temp) thus obtained is shown in Figure 4. Therein, $X_{T\{\mathrm{~A}\}}($ Temp) for each prefecture reproduces the underlying variation of $N_{T\{\mathrm{~A}\}}$ data. The optimum LSF curves for $N_{T\{\mathrm{~A}\}}$, $N_{T\{\mathrm{M}\}}$, and $N_{T\{\mathrm{~m}\}}\left[X_{T\{\mathrm{~A}\}}\right.$ (Temp), $X_{T\{\mathrm{M}\}}$ (Temp), and $X_{T\{\mathrm{~m}\}}(\mathrm{Temp})$, respectively] were similarly calculated using two dominant periodic modes in the PSDs, which are listed in the Supplementary Material (see online Supplementary Table S2). The good fit of the LSF curves to the data of $N_{T\{\mathrm{~A}\}}, N_{T\{\mathrm{M}\}}$, and $N_{T\{\mathrm{~m}\}}$ was supported by the result that the values of $\rho$ covered the upper level: $\rho=0.83-0.97$ for $N_{T\{\mathrm{~A}\}}, \rho=0.87-0.96$ for $N_{T\{\mathrm{M}\}}$, and $\rho=0.83-0.99$ for $N_{T\{\mathrm{~m}\}}$.

In the LSF curves for $N_{T\{\mathrm{~A}\}}$, that is, $X_{T\{\mathrm{~A}\}}(\mathrm{Temp})$, of the eight prefectures (Fig. 4), the patterns showed positive slopes against Temp. Notably, in Fukuoka Prefecture (Fig. $4 g$ ), for example, $X_{T\{\mathrm{~A}\}}(\mathrm{Temp})$ indicated a maximum value at Temp $=28^{\circ} \mathrm{C}$ and decreased at $28^{\circ} \mathrm{C}<\mathrm{Temp}$. This inverse $V$-shaped relationship between $X_{T\{\mathrm{~A}\}}$ (Temp) against Temp was observed in 21 of the 47 prefectures (45\%). For cases that exhibited inverse $V$-shaped slopes, we estimated maximum values of $X_{T\{\mathrm{~A}\}}(\mathrm{Temp})$ and inflection points or minimum values just before the maximum values of $X_{T\{\mathrm{~A}\}}$ (Temp). Maximum values of $X_{T}$ \{A\} (Temp) ranged from 24 to $30^{\circ} \mathrm{C}$ (Fig. 6a), and inflection points or minimum values of $X_{T\{\mathrm{~A}\}}$ (Temp) ranged from 12 to $18{ }^{\circ} \mathrm{C}$ (Fig. 6b). Each set of the values shown in Figure $6 a, b$ for $X_{T\{\mathrm{~A}\}}$ (Temp) indicated no significant correlations with latitude of the prefectures.
In the LSF curves for $N_{T\{\mathrm{M}\}}$, that is, $X_{T\{\mathrm{M}\}}(\mathrm{Temp})$ (online Supplementary Fig. S1), an inverse $V$-shaped relationship between $X_{T\{\mathrm{M}\}}(\mathrm{Temp})$ against Temp was observed for 26 of the 47 prefectures (55\%). Maximum values of $X_{T\{\mathrm{M}\}}(\mathrm{Temp})$ are shown in Figure $6 a^{\prime}$. It is worth noting that the maximum values ranged from 28 to $35^{\circ} \mathrm{C}$, a higher temperature range compared with the case of $X_{T\{\mathrm{~A}\}}$ (Temp) $\left(24-30^{\circ} \mathrm{C}\right)$ (Fig. $6 a$ ).

In the LSF curves for $N_{T\{\mathrm{~m}\}}$, that is, $X_{T\{\mathrm{~m}\}}(\mathrm{Temp})$ (online Supplementary Fig. S2), an inverse $V$-shaped relationship between $X_{T\{\mathrm{~m}\}}$ (Temp) against Temp was observed for 15 of the 47 prefectures $(32 \%)$. Inflection points or minimum values of $X_{T\{\mathrm{~m}\}}(\mathrm{Temp})$ are shown in Figure $6 b^{\prime}$. Interestingly, inflection points or minimum values ranged from 6 to $17^{\circ} \mathrm{C}$, a lower temperature range compared with the case of $X_{T}$ $\{\mathrm{A}\}$ (Temp) $\left(12-18^{\circ} \mathrm{C}\right)($ Fig. $6 b)$. Among all 47 prefectures, there were 12 in which both $X_{T\{\mathrm{~m}\}}$ (Temp) and $X_{T\{\mathrm{M}\}}(\mathrm{Temp})$ were assigned, as listed in Table 2. Both $X_{T\{\mathrm{~m}\}}$ (Temp) and $X_{T\{\mathrm{M}\}}$ (Temp) listed in Table 2 showed no significant correlations with latitude of the prefectures.

\section{Correlations between HFMD cases and RH}

Using the HFMD data (Fig. 3) and RH data, we obtained $N_{\mathrm{RH}}$ [equation (1)]; the results of $N_{\mathrm{RH}}$ are shown in Figure 7. We investigated the LSF curves of $N_{\mathrm{RH}}$, that is, $X_{\mathrm{RH}}(h)$ [equation (5)], using the same procedure as with the cases of $N_{T\{\mathrm{~A}\}}, N_{T\{\mathrm{M}\}}$, and $N_{T\{\mathrm{~m}\}}$ (Fig. 4); the results of $X_{\mathrm{RH}}(h)$ for the eight prefectures are shown in Figure 7. For all cases, the value of $N_{\mathrm{RH}}$ gradually increased with increasing $\mathrm{RH}>60 \%$. In Miyagi (Fig. $7 b$ ), for example, the value of $X_{\mathrm{RH}}(h)$ peaked at $h=80 \%$ and decreased at $80 \%<h$. This inverse $V$-shaped relationship between $X_{\mathrm{RH}}(h)$ against $h$ was observed for eight of 47 prefectures $(17 \%)$. Maximum values of $X_{\mathrm{RH}}(h)$ ranged from $70 \%$ to $85 \%$ (Fig. $8 a$ ), and inflection points or minimum values ranged from $45 \%$ to $70 \%$ (Fig. $8 b$ ). Each set of the values shown in Figure $7 a, b$ for $X_{\mathrm{RH}}(h)$ indicated no significant correlations with latitude of the prefectures.

\section{Correlations between HFMD cases and RF}

Using data of HFMD (Fig. 3) and RF, we determined $N_{\mathrm{RF}}$ [equation (1)]; the results are displayed in Figure 9. We calculated the LSF curves of $N_{\mathrm{RF}}$, that is, $X_{\mathrm{RF}}(r)$ [equation (6)], by following the same procedure as that for $N_{T\{\mathrm{~A}\}}, N_{T\{\mathrm{M}\}}$, and $N_{T\{\mathrm{~m}\}}$ (Fig. 4); 

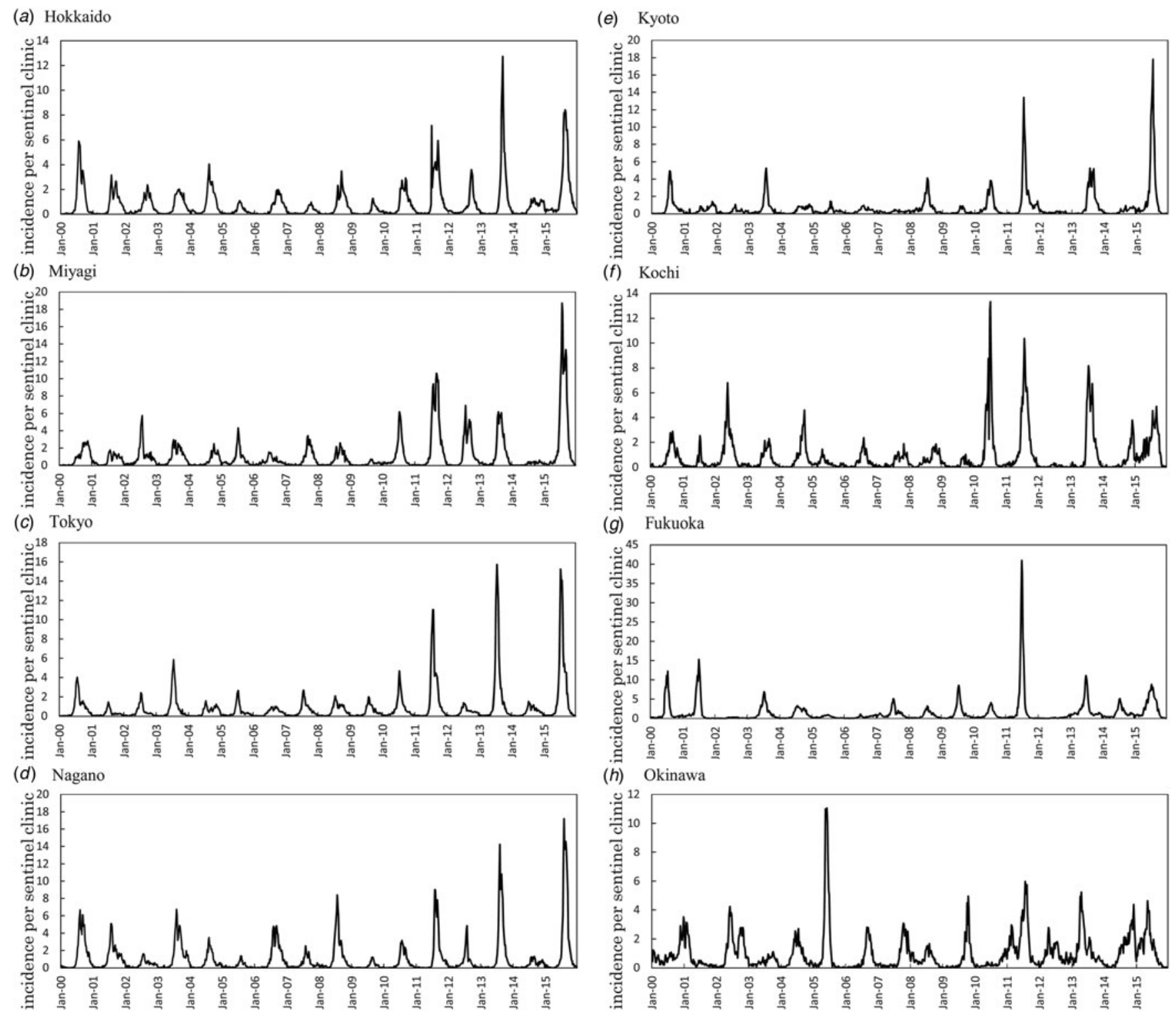
(g) Fukuoka

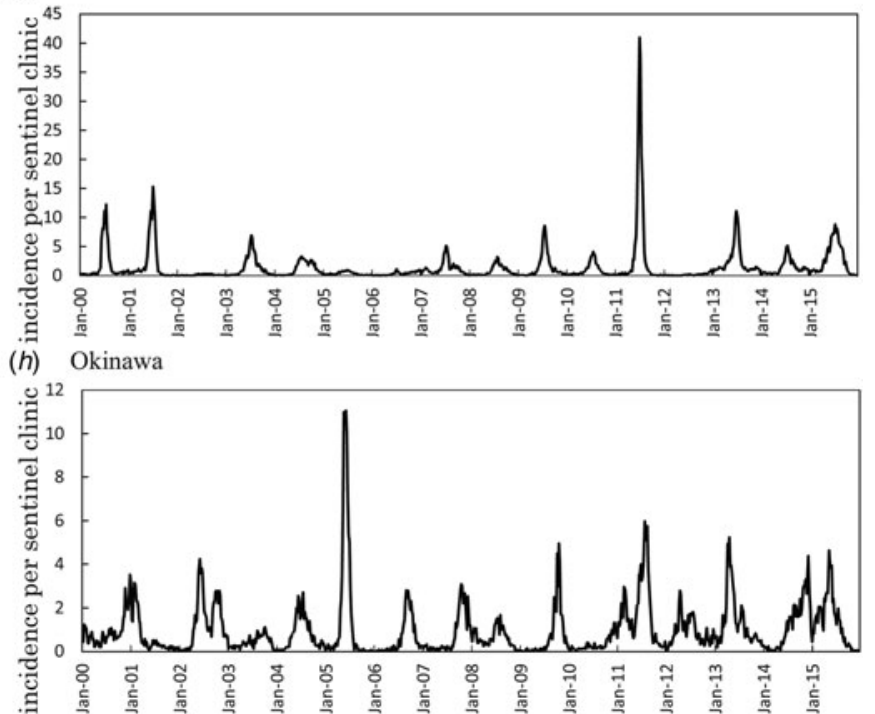


(a) Hokkaido

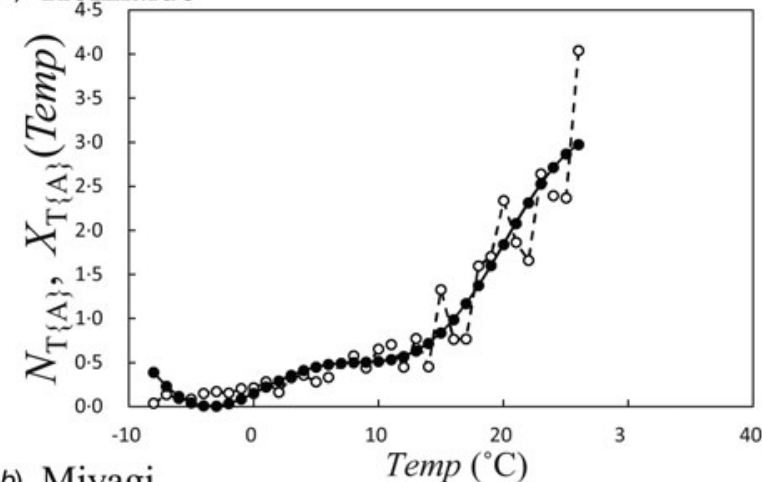

(b) Miyagi

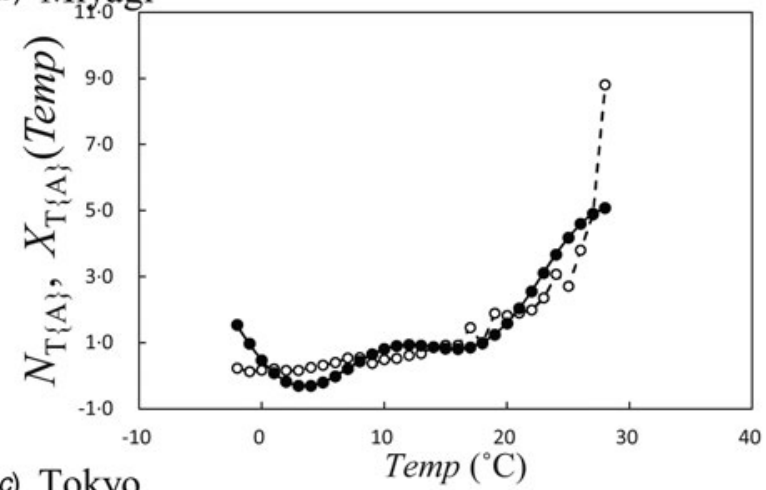

(c) Tokyo

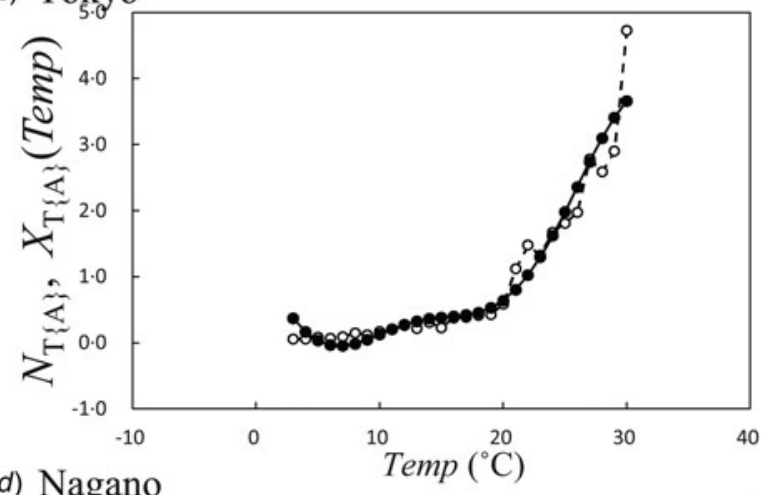

(d) Nagano

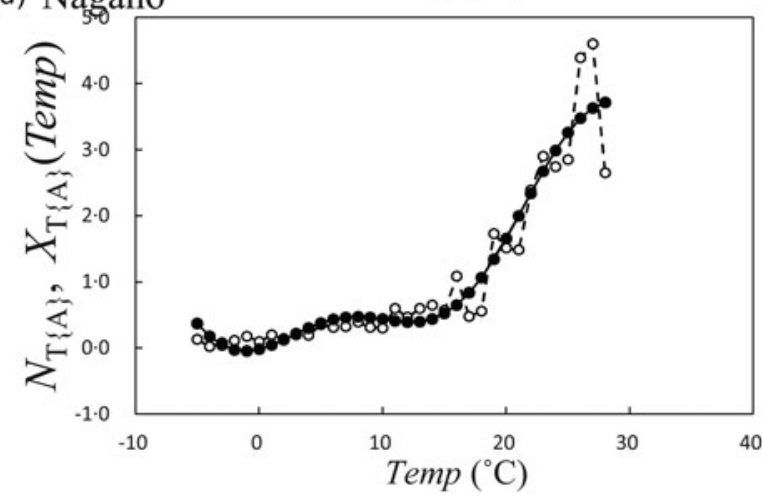

(e) Kyoto

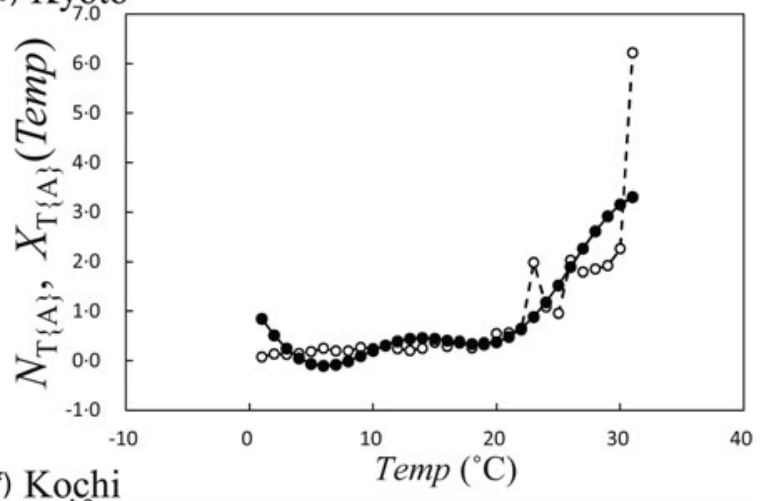

(f) Koch

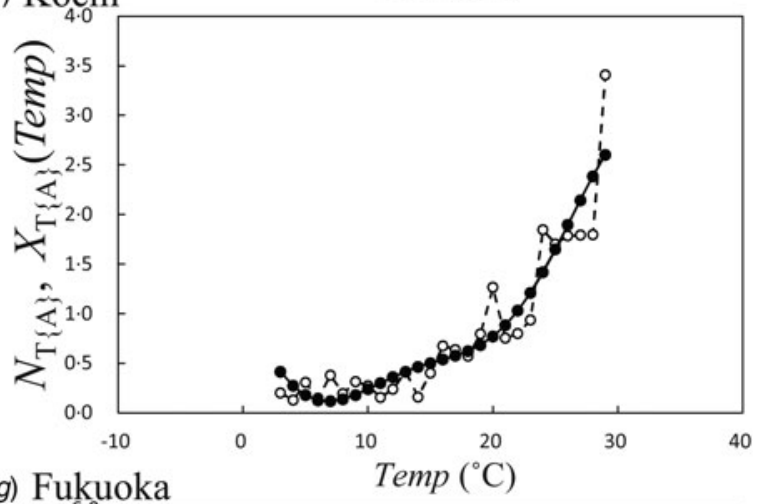

(g) Fukuoka

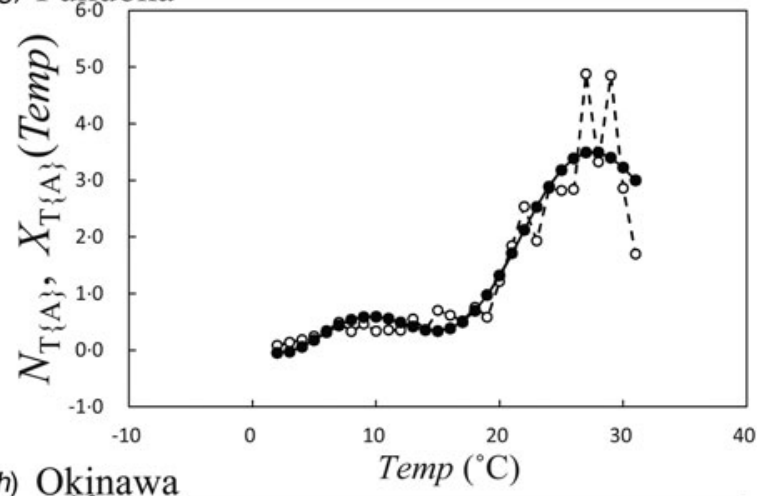

(h) Okinawa

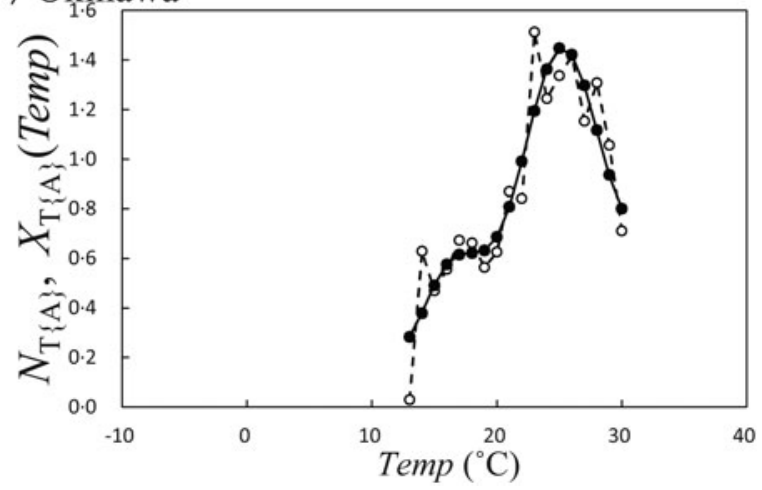

Fig. 4. Average occurrence of HFMD infection against average temperature $(T\{\mathrm{~A}\}), N_{T\{\mathrm{~A}\}}$ in equation (1), and its least squares fitting curve, $X_{T\{\mathrm{~A}\}}(\mathrm{Temp})$ in equation (4). $X_{T\{\mathrm{~A}\}}(\mathrm{Temp})$, solid line; $N_{T\{\mathrm{~A}\}}$, dashed line. (a) Hokkaido, (b) Miyagi, $(c)$ Tokyo, (d) Nagano, (e) Kyoto, (f) Kochi, (g) Fukuoka, and (h) Okinawa. 
(a) Hokkaido

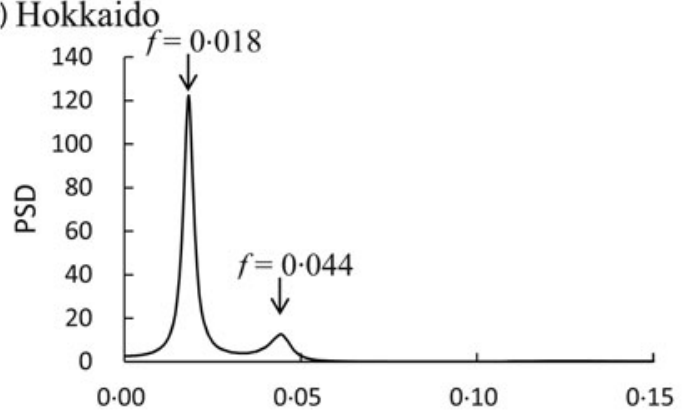

(b) Miyagi

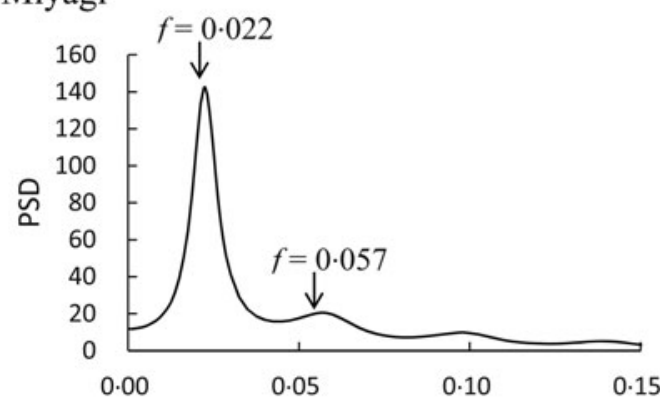

(c) Tokyo

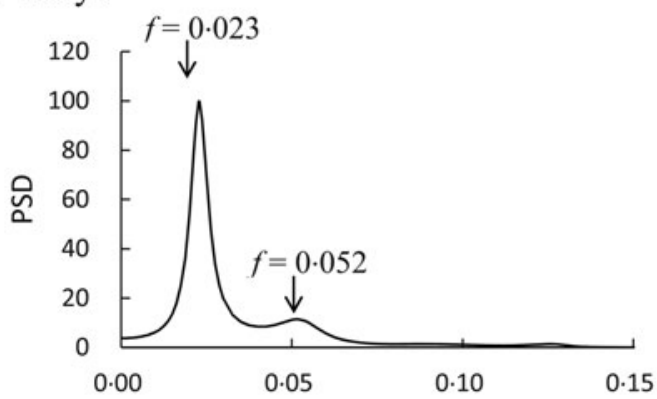

(d) Nagano

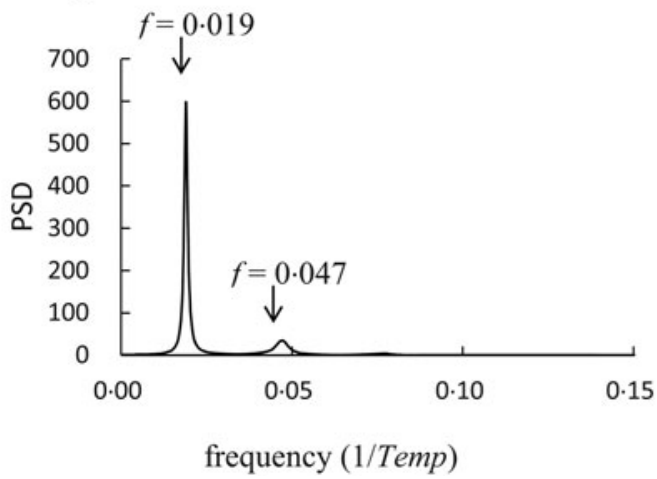

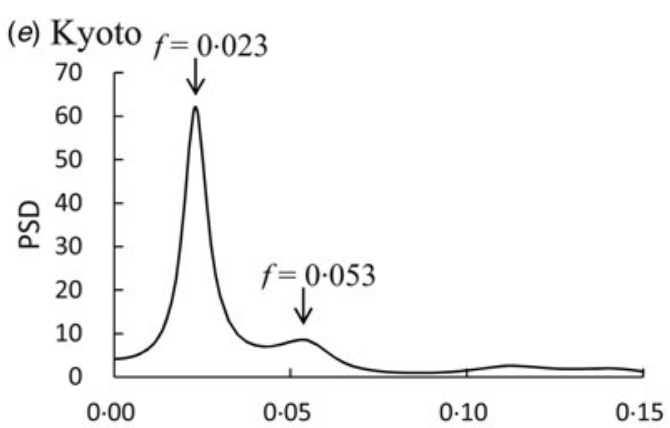
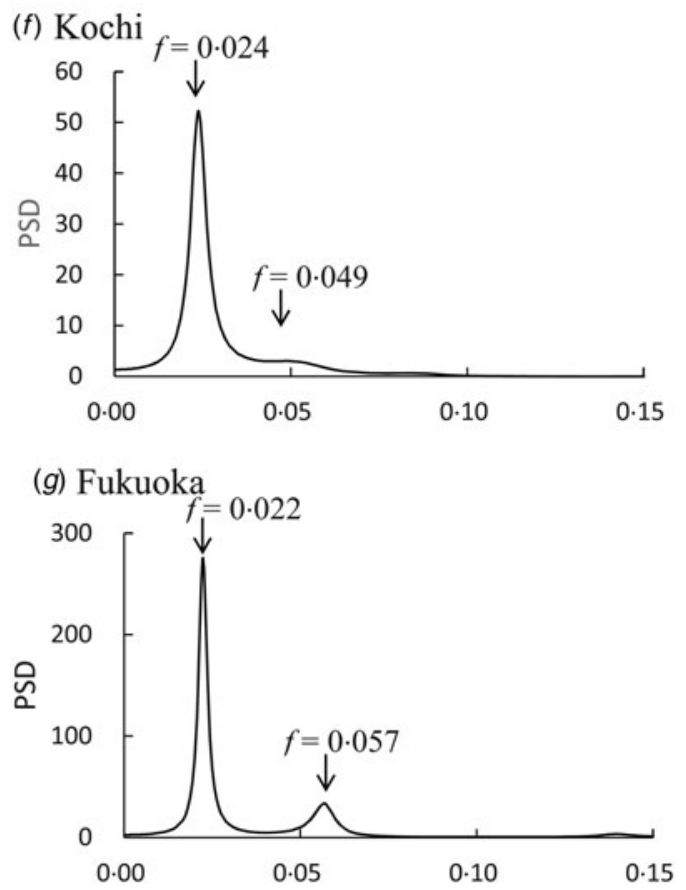

(h) Okinawa

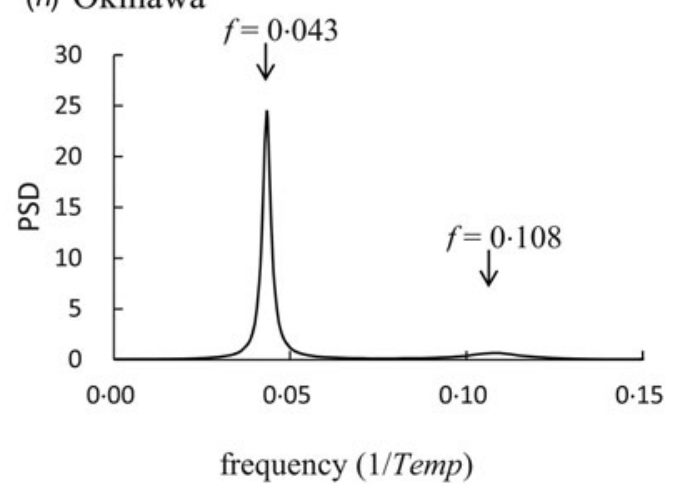

Fig. 5. Power spectral densities of $N_{T\left\{\mathrm{~A}_{\}}\right.}$. (a) Hokkaido, (b) Miyagi, (c) Tokyo, (d) Nagano, (e) Kyoto, (f) Kochi, (g) Fukuoka, and $(h)$ Okinawa.

results of $X_{\mathrm{RF}}(r)$ for the eight prefectures are shown in Figure 9. For Miyagi, Tokyo, and Kyoto (Fig. 9b, $c$ and $e$, respectively), the values of $X_{\mathrm{RF}}(r)$ increased with increasing $r<300 \mathrm{~mm}$. For Kochi, Fukuoka, and Okinawa (Fig. 9f-h, respectively), the values of
$X_{\mathrm{RF}}(r)$ still increased at $300 \mathrm{~mm} \leqslant r: 270 \mathrm{~mm} \leqslant r<$ $360 \mathrm{~mm}$ for Kochi (Fig. 9f), $270 \mathrm{~mm} \leqslant r<420 \mathrm{~mm}$ for Fukuoka (Fig. 9g), and $360 \mathrm{~mm} \leqslant r<480 \mathrm{~mm}$ for Okinawa (Fig. 9h). With respect to Hokkaido and Nagano (Fig. 9a, d, respectively), it was difficult 
(a)

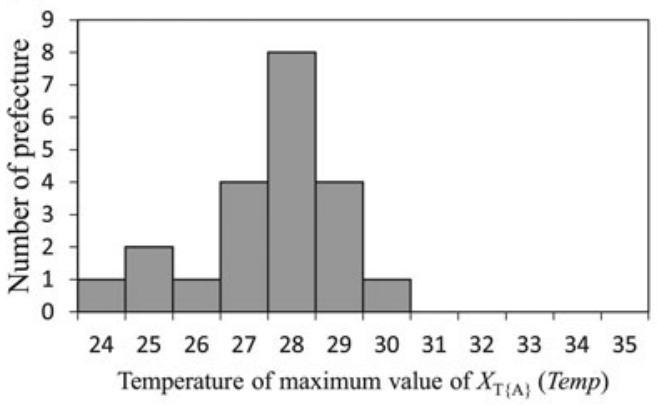

$\left(a^{\prime}\right)$

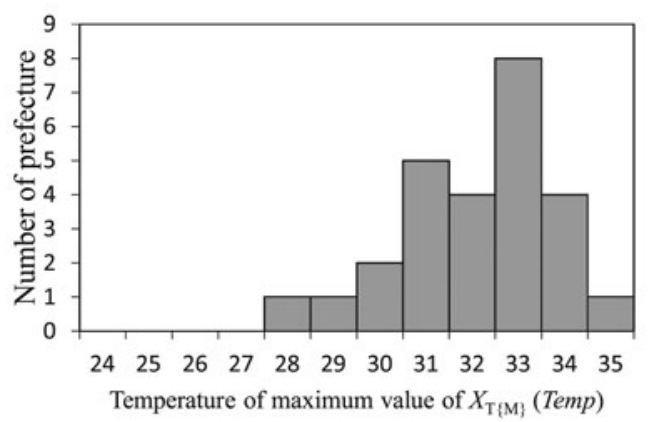

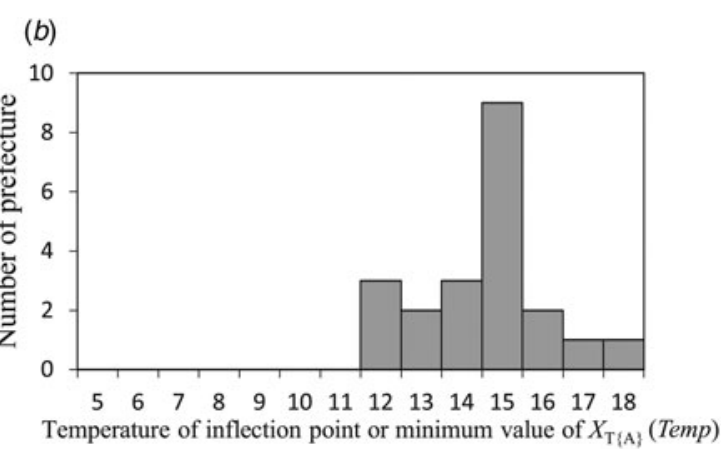

$\left(b^{\prime}\right)$

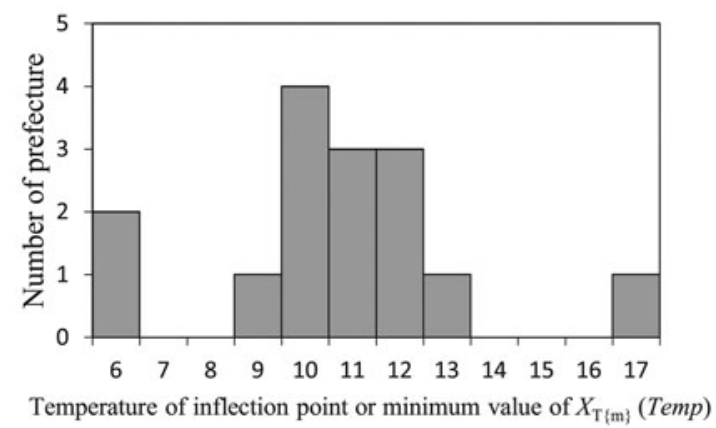

Fig. 6. Number of prefectures against temperature for $X_{T\{\mathrm{~A}\}}(\mathrm{Temp}), X_{T\{\mathrm{M}\}}(\mathrm{Temp})$, and $X_{T\{\mathrm{~m}\}}$ (Temp). (a) Number of prefectures against temperature for maximum value of $X_{T\{\mathrm{~A}\}}(\mathrm{Temp}),\left(a^{\prime}\right)$ number of prefectures against temperature for maximum value of $X_{T\{\mathrm{M}\}}$ (Temp), $(b)$ number of prefectures against temperature for inflection point or minimum value of $X_{T\{\mathrm{~A}\}}(\mathrm{Temp})$, and $\left(b^{\prime}\right)$ number of prefectures against temperature for inflection point or minimum value of $X_{T\{\mathrm{~m}\}}(\mathrm{Temp})$.

Table 2. Prefectures where both $X_{T\{M\}}($ Temp) and $X_{T\{m\}}($ Temp) were assigned, and the values of each prefecture's $X_{T\{M\}}\left(\right.$ Temp) and $X_{T\{m\}}($ Temp)

\begin{tabular}{lll}
\hline \hline Prefectures & $X_{T\{\mathrm{~m}\}}$ & $X_{T\{\mathrm{M}\}}$ \\
\hline Akita & 10 & 29 \\
Nagano & 9 & 33 \\
Nara & 11 & 32 \\
Shimane & 10 & 30 \\
Okayama & 12 & 34 \\
Hiroshima & 11 & 30 \\
Yamaguchi & 11 & 34 \\
Fukuoka & 12 & 33 \\
Saga & 12 & 32 \\
Kumamoto & 6 & 31 \\
Oita & 10 & 31 \\
Okinawa & 17 & 31 \\
\hline \hline
\end{tabular}

to find a relationship between $X_{\mathrm{RF}}(r)$ and $r$ because of a relatively small amount of rainfall.

\section{DISCUSSION}

The present results for $T\{\mathrm{~A}\}$ demonstrated a lower threshold at $12{ }^{\circ} \mathrm{C}$ (Fig. 6b) and a higher threshold at $30^{\circ} \mathrm{C}$ (Fig. 6a). This supports our previous result that the risk of HFMD infection is high at $10^{\circ} \mathrm{C} \leqslant$ Temp $<25^{\circ} \mathrm{C}$ in Wuhan, China [4]. However, the results for $T\{\mathrm{M}\}$ and $T\{\mathrm{~m}\}$ indicated a lower threshold at $6{ }^{\circ} \mathrm{C}$ (Fig. $6 b^{\prime}$ ) and a higher threshold at $35^{\circ} \mathrm{C}$ (Fig. $6 a^{\prime}$ ). These findings can help with control of HFMD at temperatures $6{ }^{\circ} \mathrm{C} \leqslant \mathrm{Temp} \leqslant 35^{\circ} \mathrm{C}$, which is a wider temperature range than $12^{\circ} \mathrm{C} \leqslant$ Temp $\leqslant 30^{\circ} \mathrm{C}$ for $T\{\mathrm{~A}\}$ (Fig. $6 a, b$ ). Based on this result, we recommend the use of maximum and minimum temperatures rather than the average temperature, to estimate the temperature threshold of HFMD infections.

Many studies have found threshold effects between meteorological factors and HFMD epidemics [1-6]. Our findings showed that for 26 and 15 of the 47 prefectures, the risk function of $T\{\mathrm{M}\}$ and $T\{\mathrm{~m}\}$, respectively, approximated an inverse $V$-shaped curve with HFMD incidence, and the threshold of temperature ranged from 6 to $35^{\circ} \mathrm{C}$ (Fig. $6 a^{\prime}, b^{\prime}$ ). This association may be partially explained by the fact that temperatures ranging from 2 to $27^{\circ} \mathrm{C}$ provide a more favourable environment for enterovirus epidemics [27], making it easier 
(a) Hokkaido

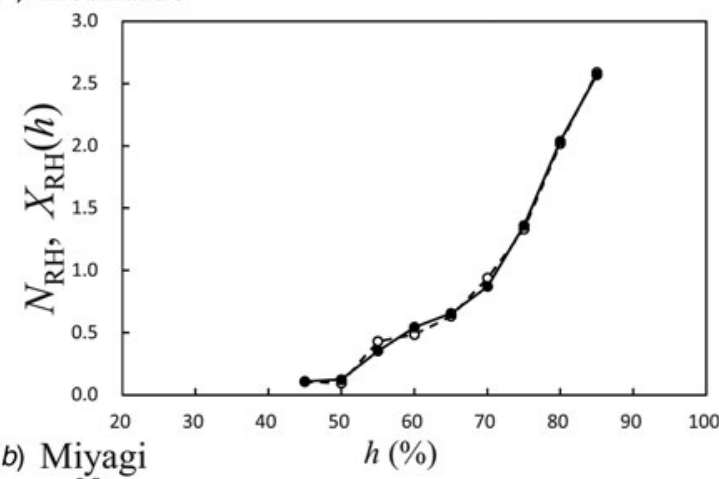

(b) Miyagi

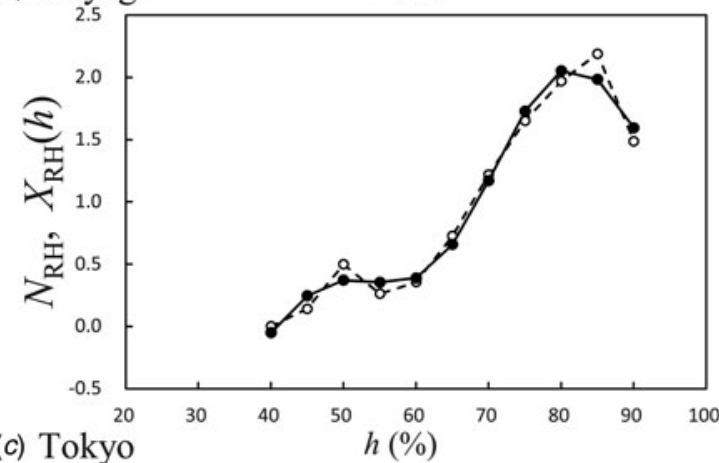

(c) Tokyo

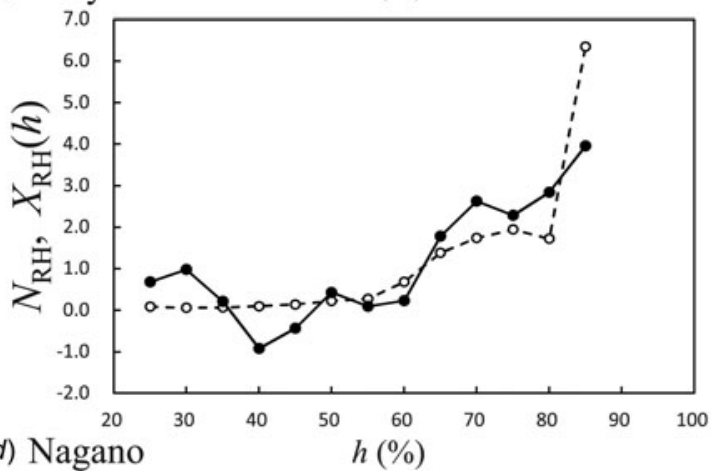

(d) Nagano

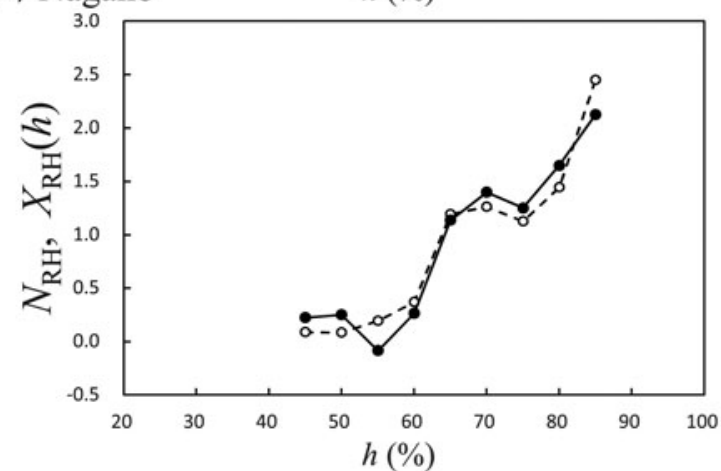

(e) Kyoto
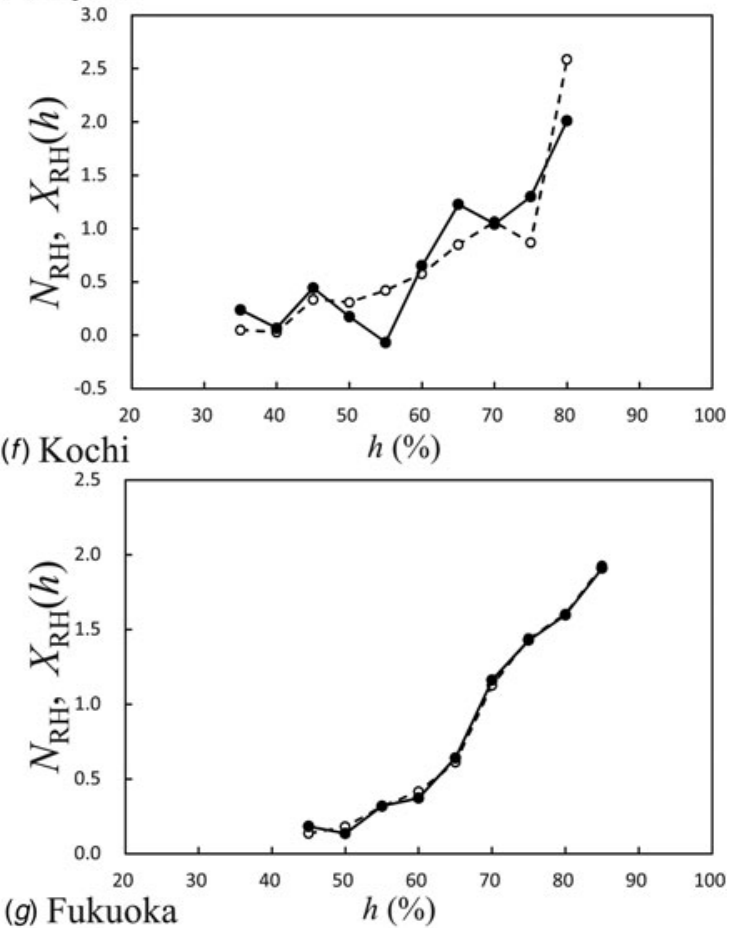

(g) Fukuoka $\quad h(\%)$

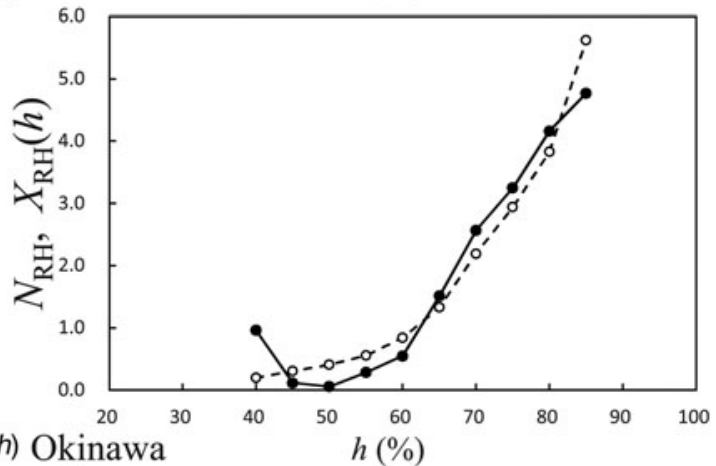

(h) Okinawa $\quad h(\%)$

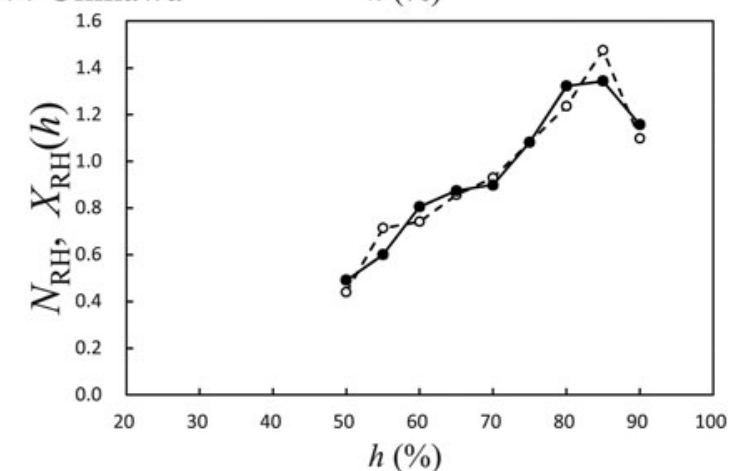

Fig. 7. Average HFMD infection occurrence against relative humidity (RH), $N_{\mathrm{RH}}$ in equation (1), and its least squares fitting curve, $X_{\mathrm{RH}}(h) . X_{\mathrm{RH}}(h)$ in equation (5), solid line; $N_{\mathrm{RH}}$, dashed line. (a) Hokkaido, (b) Miyagi, (c) Tokyo, $(d)$ Nagano, $(e)$ Kyoto, $(f)$ Kochi, $(g)$ Fukuoka, and (h) Okinawa.

for people to be infected. However, extreme temperatures may make it difficult for people to take part in public activities, which makes them less likely to be infected [6].
For $\mathrm{RH}$, there was a lower threshold at $45 \%$ and a higher threshold at $85 \%$ (Fig. $8 a, b$ ). This result supports that of Zhang et al. [28], who found a threshold of RH ranging from $45 \%$ to $85 \%$ in Shenzhen, China. 
(a)

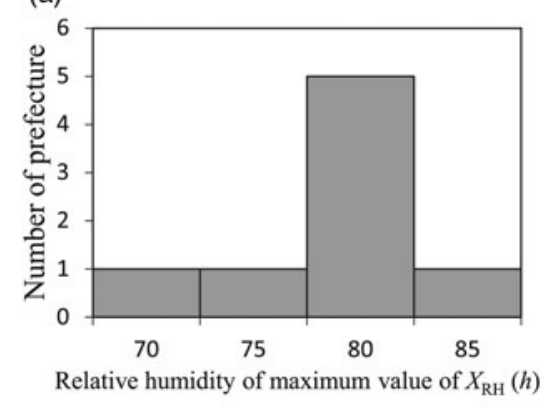

(b)

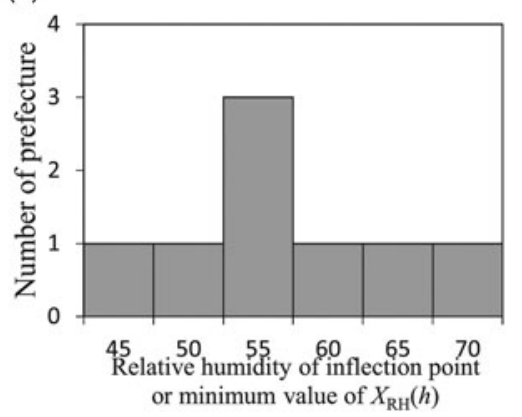

Fig. 8. Number of prefectures against relative humidity $(\mathrm{RH})$ for $X_{\mathrm{RH}}(h)$. (a) Number of prefectures against relative humidity for maximum value of $X_{\mathrm{RH}}(h)$, and $(b)$ number of prefectures against temperature for inflection point or minimum value of $X_{\mathrm{RH}}(h)$.

Within a certain range of $\mathrm{RH}$, higher humidity could facilitate viral attachment to the surface of objects, including toys [29], which is also supported by experimental studies wherein viruses exhibit a rapid rate of decline during the dry season [30].

For rainfall (Fig. 9), our findings of a positive correlation between reported cases of HFMD and rainfall in all cases, except for Hokkaido and Nagano (Fig. $9 a, d$, respectively), are supported by our previous study. In that study, we demonstrated that Wuhan, China, which is in an area with a subtropical wet monsoonal climate, experiences more outbreaks of HFMD during the rainy season [4]. The large values of $X_{\mathrm{RF}}(r)$ at $300 \mathrm{~mm} \leqslant r$ for Kochi and Fukuoka in western Japan (Fig. $9 f, g$, respectively) and Okinawa in southern Japan (Fig. 9h) might result from typhoons, which often land and develop in these areas during July-November, as well as the East Asian rainy seasons during June-July in early summer and during November-December in early winter.

Until recently, EV-A71 and coxsackievirus A16 (CA16) have been considered the main causes of HFMD in Japan. However, in 2009, coxsackievirus A6 (CA6) began to emerge as a cause of HFMD. Large HFMD outbreaks in the country were caused by CA6 in 2011, 2013, and 2015. Among the prefectures investigated in this study, bimodal seasonality of HFMD was observed in Okinawa Prefecture in southern Japan (Fig. 1). The causative agent of HFMD in Okinawa is not known because only 26 strains of enterovirus have been reported in Okinawa between 1986 and 2016. As a result, the bimodal seasonality of HFMD in Okinawa in 2002 and 2011 is yet to be explained. Because the average value of $T\{\mathrm{~m}\}$ in Okinawa $\left(21 \cdot 1{ }^{\circ} \mathrm{C}\right.$ in Table 1$)$ is above $6{ }^{\circ} \mathrm{C}$, Okinawa is the only prefecture that belongs to the subtropical zone in Japan. It is possible that the bimodal HFMD epidemics in Okinawa can be explained by multiple epidemics of CA16, EV-A71, and CA6 within 1 year. One good example of unique enterovirus circulation in Okinawa is a local outbreak of haemorrhagic conjunctivitis that was caused by coxsackievirus A24 (CA24) [31]. No outbreaks of CA24 were observed in Japan, except for in Okinawa, during the period of this study.

Using HFMD surveillance data collected in all 47 prefectures by Japan's nationwide surveillance system for infectious diseases, we confirmed that there is no latitude dependence of maximum values, and inflection point or minimum value of $X_{T\{\mathrm{~A}\}}(\mathrm{Temp})$, $X_{T\{\mathrm{M}\}}$ (Temp), $X_{T\{\mathrm{~m}\}}$ (Temp) (Fig. 6), and $X_{\mathrm{RH}}(h)$ (Fig. 8). The country is divided into prefectures, each of which is further subdivided into cities with respective wards and blocks. In the present study, we used prefecture data of HFMD because prefecture measures are the minimum unit of measurement released by the NESID in Japan. To investigate spatial characteristics of HFMD incidence in Japan in more detail, such as the spatial heterogeneity [32, 33], further studies using data from cities, wards, and/or blocks should be conducted.

Causative pathogens of HFMD, such as EV-A71, CA16, and CA6, may affect the disease duration or epidemic peaks [34, 35]; however, in the present study, there was no information available on these pathogens. Under this condition, the use of equations (1) and (2) in this study enabled us to efficiently examine whether HFMD transmission in the 47 prefectures was related to meteorological factors. Information on the causative agents of HFMD for each Japanese prefecture can assist in future investigation of those 
(a) Hokkaido

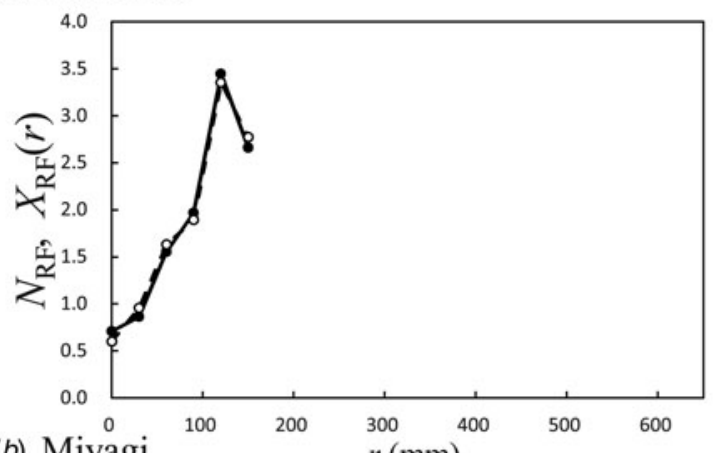

(b) Miyagi $r(\mathrm{~mm})$

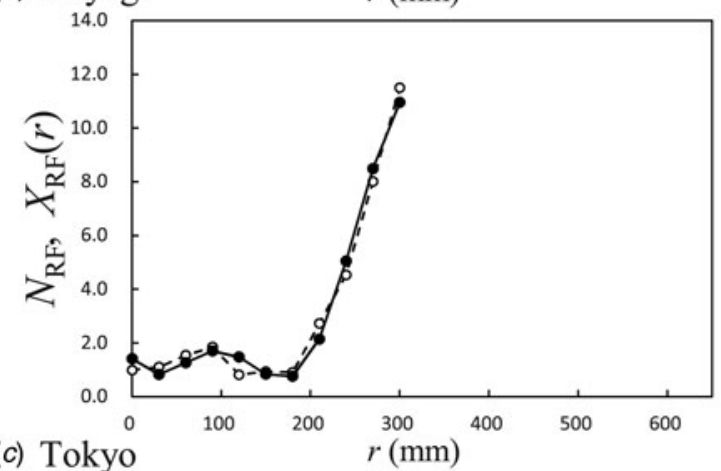

(c) Tokyo

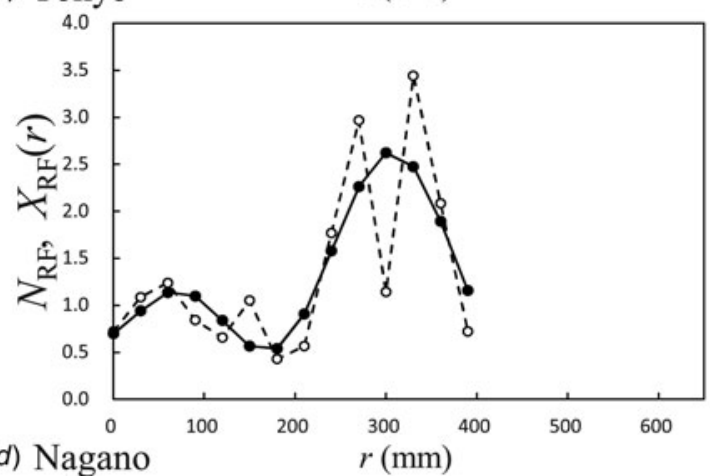

(d) Nagano

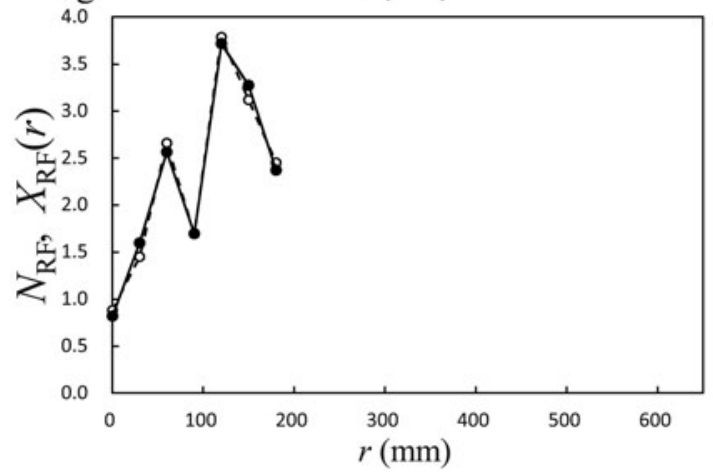

(e) Kyoto
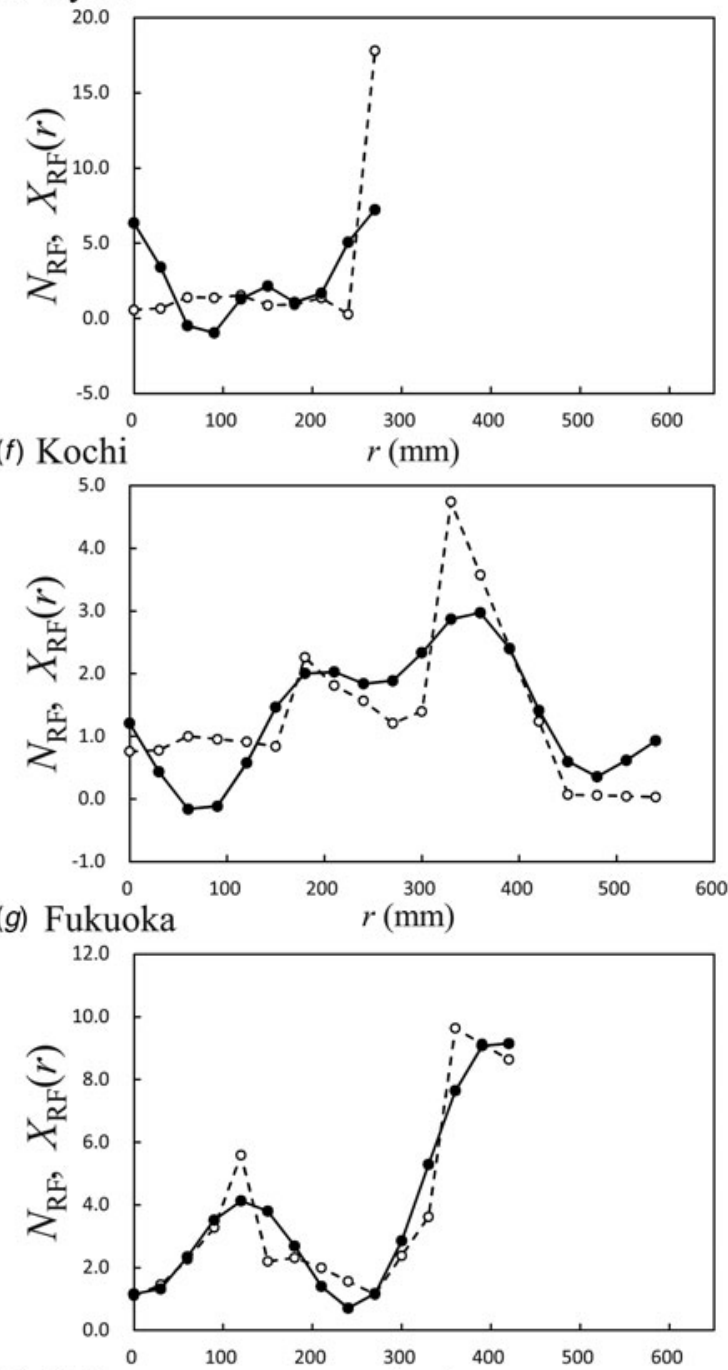

(h) Okinawa

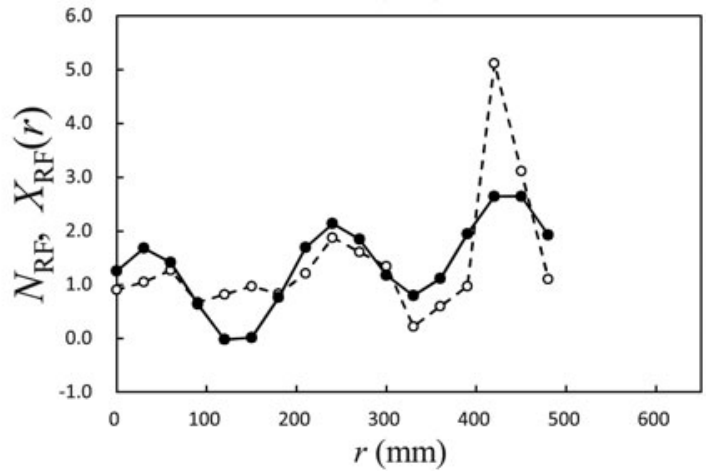

Fig. 9. Average HFMD infection occurrence against total rainfall (RF), $N_{\mathrm{RF}}$ in equation (1), and its least squares fitting curve, $X_{\mathrm{RF}}(r) . X_{\mathrm{RF}}(r)$ in equation (6), solid line; $N_{\mathrm{RF}}$, dashed line. (a) Hokkaido, (b) Miyagi, (c) Tokyo, (d) Nagano, $(e)$ Kyoto, $(f)$ Kochi, $(g)$ Fukuoka, and $(h)$ Okinawa.

meteorological factors related to HFMD transmission in the country, using more sophisticated methods such as generalized additive models [36] and non-linear regression models [37].
A limitation of the present study is that we used weekly data of HFMD, whereas we used daily data for meteorological factors, because weekly measures are the minimum unit of measurement released by 
the NESID. We investigated monthly HFMD and meteorological data for Fukuoka Prefecture to compare the results shown in Figure $2 d$. We confirmed that, with monthly data, we did not obtain the inverse $V$-shaped curves obtained for weekly data (see online Supplementary Fig. S3). Furthermore, we confirmed that, for the eight prefectures (Fig. 3), the variance of yearly temperature was relatively small compared with the variance of yearly incidence rate of HFMD (see online Supplementary Table S3). Thus, we consider that the monthly and yearly data are too rough to extract a correlation between HFMD data and meteorological data. Further studies using daily data of HFMD should be conducted.

In conclusion, we demonstrated that the ambient temperature and relative humidity thresholds can be extracted from NESID data of the 47 prefectures in Japan by constructing a systematic procedure with a clear criterion of adequate estimation. We recommend the use of maximum and minimum temperatures to estimate the temperature threshold of HFMD epidemics. The obtained results might aid in the prediction of HFMD epidemics and preparation for the effect of climatic changes on HFMD epidemiology.

\section{SUPPLEMENTARY MATERIAL}

The supplementary material for this article can be found at https://doi.org/10.1017/S0950268817001820.

\section{APPENDIX}

\section{MEM spectral analysis}

MEM-PSD $P(f)$ (where $f$ represents frequency) for the time series with equal sampling interval $\Delta t$, can be expressed by

$$
P(f)=\frac{P_{m} \Delta t}{\left|1+\sum_{k=-m}^{m} \gamma_{m . k} \exp [-i 2 \pi f k \Delta t]\right|^{2}},
$$

where the value of $P_{m}$ is the output power of a prediction-error filter of order $m$ and $\gamma_{m, k}$ is the corresponding filter order. The value of the MEM-estimated period of the $n$th peak component $T_{n}\left(=1 / f_{n}\right.$; where $f_{n}$ is the frequency of the $n$th peak component) can be determined by the positions of the peaks in the MEM-PSD.

\section{ACKNOWLEDGEMENTS}

The authors thank Analisa Avila, ELS, from Edanz Group (www.edanzediting.com/ac) for editing a draft of this manuscript. This study was supported by JSPS KAKENHI, Grant Numbers JP16K09061, JP25460769, JP25305022.

\section{ETHICAL STANDARDS}

This study was approved by the Ethical Committee of the National Institute of Infectious Diseases on 8 January 2015.

\section{REFERENCES}

1. Song Y, et al. Time series analyses of hand, foot and mouth disease integrating weather variables. PLoS ONE 2015; 10: e0117296.

2. Ma E, et al. Is hand, foot and mouth disease associated with meteorological parameters? Epidemiology and Infection 2010; 138: 1779-1788.

3. Hii YL, Rocklöv J, Ng N. Short term effects of weather on hand, hoot and mouth disease. PLoS ONE 2011; 6: e16796. doi: 10.1371/journal.pone.0016796.

4. Chen B, et al. Time series analysis of reported cases of hand, foot, and mouth disease from 2010 to 2013 in Wuhan, China. BMC Infectious Diseases 2015; 15: 495-509.

5. Chang HL, et al. The association between enterovirus 71 infections and meteorological parameters in Taiwan. PLOS ONE 2012; 7: e46845. doi: 10.1371/journal.pone.0046845.

6. Liao J, et al. Short-term effect of climatic variables on hand, foot, and mouth disease in mainland China, 2008-2013: a multilevel spatial Poisson regression model accounting for overdispersion. PLOS ONE 2016; 25: e0147054. doi: 10.1371/journal.pone.0147054.

7. Dowell SF. Seasonal variation in host susceptibility and cycles of certain infectious diseases. Emerging Infectious Diseases 2001; 7: 369-374.

8. Chang LY, et al. Risk factors of enterovirus 71 infection and associated hand, foot, and mouth disease/herpangina in children during an epidemic in Taiwan. Pediatrics 2002; 109: e88.

9. Chang LY, et al. Transmission and clinical features of enterovirus 71 infections in household contacts in Taiwan. JAMA 2004; 291: 222-227.

10. Meeburg BG, Kijllstra A. Changing climate-changing pathogens: Toxoplasma gondii in North-Western Europe. Parasitology Research 2009; 105: 17-24.

11. Patz JA, et al. Impact of regional climate change on human health. Nature 2005; 438: 310-317.

12. Harigane $\mathbf{K}$, et al. The role of temperature in reported chickenpox cases from 2000 to 2011 in Japan. Epidemiology and Infection 2015; 143: 2666-2678.

13. Onozuka D, Hashizume M. The influence of temperature and humidity on the incidence of hand, foot, and 
mouth disease in Japan. Science of the Total Environment 2011; 410: 119-125.

14. Ohtomo N, et al. New method of time series analysis and its application to Wolf's sunspot number data. Japanese Journal of Applied Physics 1994; 33: 28212831.

15. Sumi A, et al. Effect of temperature, relative humidity and rainfall on dengue fever and leptospirosis infections in Manila, the Philippines. Epidemiology and Infection 2017; 145: 78-86.

16. Infectious Diseases Surveillance Center. Infectious Diseases Weekly Report (http://www.nih.go.jp/niid/ja/ idwr.html). Accessed 7 March 2017.

17. Nagai M. Surveillance of infectious diseases. Journal of Public Health Practice 2005; 69: 864-869 (in Japanese).

18. Japan Meteorological Agency. Weather, Climate \& earthquake information (http://www.jma.go.jp/jma/ kishou/know/amedas/kaisetsu.html). Accessed 11 May 2017 (in Japanese).

19. Japan Meteorological Agency. Weather, Climate \& earthquake information (http://www.jma.go.jp/jma/ indexe.html). Accessed 7 March 2017.

20. Donald Ahrens C. Meteorology Today: An Introduction to Weather and Climate, 10th edn. Boston: Cengage Learning, 2012.

21. Chan PKS, et al. Seasonal influenza activity in Hong Kong and its association with meteorological variations. Journal of Medical Virology 2009; 81: 1797-1806.

22. Armitage P, Berry G, Matthews JNS. Statistical Methods in Medical Research. 4th edn. Oxford: Blackwell Science, 2012.

23. Mattfeldt T. Nonlinear deterministic analysis of tissue texture: a serological study on mastopathic and mammary cancer tissue using chaos theory. Journal of Microscopy 1997; 185: 47-66.

24. Mise K, et al. Spectral study of spatial series data of pathologic tissue: a study on small intestine in ICR mouse. Japanese Journal of Applied Physics 2009; 48: 017001-1-017001-8.

25. Sumi A, et al. Time-series analysis of hepatitis A, B, C and $\mathrm{E}$ infections in a large Chinese city: application to prediction analysis. Epidemiology and Infection 2013; 141: 905-915.
26. Sumi A, et al. Effect of temperature, relative humidity and rainfall on rotavirus infections in Kolkata, India. Epidemiology and Infection 2013; 141: 1652-1661.

27. Salo R, Cliver D. Effect of acid PH, salts, and temperature on the infectivity and physical integrity of enteroviruses. Archives of Virology 1976; 52: 269-282.

28. Zhang Z, et al. Short-term effects of meteorological factors on hand, foot and mouth disease among children in Shenzen, China: non-linearity, threshold and interaction. Science of the Total Environment 2016; 539: 576-582.

29. Wong S, et al. Human enterovirus 71 and hand, foot and mouth disease. Epidemiology and Infection 2010; 138: 1071-1089.

30. Abad FX, Pinto RM, Bosch A. Survival of enteric viruses on environmental fomites. Applied and Environmental Microbiology 1994; 60: 3704-3710.

31. Harada K, et al. Virological and epidemiological analysis of coxsackievirus A24 variant epidemic of acute hemorrhagic conjunctivitis in Okinawa, Japan, in 2011. Journal of Clinical Ophthalmology 2015; 15: 1085-1092.

32. Liao J, et al. Short-term effects of climatic variables on hand foot, and mouth disease in mainland China, 2008 2013: a multilevel spatial Poisson regression model accounting for overdispersion. PLoS ONE 2016; 11: $\mathrm{e} 0147054$.

33. Liu Y, et al. Spatio-temporal analysis of the relationship between climate and hand, foot, and mouth disease in Shandong province, China, 2008-2012. BMC Infectious Diseases 2015; 15: 146-153.

34. Lum LC, et al. Fatal enterovirus 71 encephalomyelitis. Journal of Pediatrcs 1998; 133: 795-798.

35. Tnag JH, et al. Latitude-based approach for detecting aberrations of hand, foot, and mouth disease epidemics. BMC Medical Informatics and Decision Making 2015; 15: 113-126.

36. Huang Y, et al. Effect of meteorological variables on the incidence of hand, foot, and mouth disease in children: a time-series analysis in Guangzhou, China. BMC Infectious Diseases 2013; 13: 134.

37. Takahashi S, et al. Hand, foot and mouth disease in China: modeling epidemic dynamics in enterovirus serotypes and implications for vaccination. PLoS Medicine 2016; 13: e1001958. 